INRA Prod. Anim., 2017, 30 (4), 363-380

\title{
Quelles concurrences et synergies entre cultures et élevage dans les territoires de polyculture-élevage?
}

\author{
J. RYSCHAWY', M. BENOIT ${ }^{2}$, N. HOSTIOU ${ }^{3}$, C. DELFOSSE \\ ${ }^{\prime}$ UMR AGIR, INRA, Université de Toulouse, INPT, 31326, Castanet-Tolosan, France \\ 2 Université Clermont Auvergne, INRA, Vetagro Sup, UMR Herbivores, 63122, Saint-Genès-Champanelle, France \\ ${ }^{3}$ Université Clermont Auvergne, INRA, AgroParisTech, Irstea, VetAgro Sup, UMR Territoires, \\ 63000, Clermont-Ferrand, France \\ ${ }_{4}^{4}$ Université de Lyon, Laboratoire d'études rurales EA3738, 69363, Lyon, France \\ Courriel : julie.ryschawy@inra.fr
}

Les territoires dans lesquels cohabitent cultures et élevages sont de plus en plus mis en avant comme présentant des opportunités pour une agriculture plus agroécologique. Pourtant, nous montrons au travers de cas d'études français que la coexistence entre grandes cultures et élevage se traduit souvent par une concurrence. Nous proposons dans cet article des leviers permettant d'intégrer réellement cultures et élevage pour créer des complémentarités au niveau des exploitations et des territoires de polyculture-élevage.

La PolyCulture-Élevage (PCE) est aujourd'hui considérée par de nombreux auteurs comme un idéal agronomique (Hendrickson et al 2008, Lemaire et al 2014), voire un modèle pour l'agroécologie (Bonaudo et al 2014). Associer productions animales et végétales conférerait des bénéfices économiques, sociaux et environnementaux aux exploitations par rapport à la spécialisation (Moraine et al 2014). Malgré ces intérêts potentiels, les exploitations de polycultureélevage sont en déclin en France et dans toute l'Union Européenne, en lien notamment avec un fort besoin de main-d'œuvre pour combiner cultures et élevage (Ryschawy et al 2013). De plus, la meilleure rentabilité des grandes cultures et leur soutien par la PAC ont induit une forte concurrence sur les surfaces, menaçant le maintien des exploitations de polyculture-élevage (Veysset et al 2005).

De nouvelles opportunités sont néanmoins offertes avec une meilleure intégration des activités d'élevage et de culture, en particulier de la production fourragère, $i$ ) au sein des exploitations (Havet et al 2014) ou ii) au niveau de nouvelles formes d'organisation, au sein de collectifs d'exploitations ou de territoires (Martin et al 2016). Au-delà de ces considérations générales et de l'influence générale des marchés et des politiques publiques, les performances des exploitations et des territoires de poly- culture-élevage sont très diverses en lien avec les formes que la PCE peut prendre, la coordination effective entre cultures et élevage étant plus ou moins importante. Ainsi, les bouquets de services que la polyculture-élevage peut fournir sont très divers et liés au contexte pédoclimatique mais aussi socio-économique local.

L'objectif de cet article est de montrer en quoi les grandes cultures et l'élevage entrent en concurrence dans les territoires où ils cohabitent et de proposer des leviers d'actions pour favoriser des synergies. Pour cela, nous éclairerons la diversité des bouquets de services fournis par les systèmes de polyculture-élevage dans un contexte de concurrence des grandes cultures depuis plusieurs décennies. Le concept de bouquet de services nous permet de considérer les multiples services d'approvisionnement, environnementaux, culturels et de vitalité territoriale fournis en un même lieu et temps et ainsi de considérer les synergies ou antagonismes entre services (Ryschawy et al 2015). Nous nous basons sur des études de cas dont une analyse transversale nous permet de faire émerger des contraintes et opportunités dans les territoires où cohabitent culture et élevage, et enfin proposer des leviers d'action pour gérer les compromis entre services dans les exploitations et les territoires.

\section{$1 /$ Les territoires où cohabi- tent cultures et élevage : entre concurrence et cohabitation}

Pour illustrer un gradient de niveau de concurrence entre cultures et élevage, nous avons retenu trois territoires emblématiques français dans lesquels grandes cultures et élevage cohabitent. Nous avons donc volontairement choisi des territoires contrastés en termes de part relative de grandes cultures et d'élevage : le Montmorillonnais, le bassin TarnAveyron et la Bresse (figure 1). Les données sont issues de la bibliographie existante sur chacun des terrains. Il n'y a donc pas eu d'étude spécifique conduite en même temps sur les trois terrains, ce qui explique la diversité des indicateurs mobilisés. Pour expliciter l'évolution de la concurrence entre cultures et élevage, nous présenterons l'évolution des systèmes depuis 1950 dans chacun de ces territoires puis les services et impacts de l'élevage. Pour cela, nous considérons les trajectoires d'évolution des systèmes locaux, nous permettant de considérer les changements de pratiques dans les systèmes et les causes issues des contextes pédoclimatique et socio-économique (Ryschawy et al 2013). Nous analyserons en particulier les bouquets de services issus de l'élevage dans chacun des territoires pour mettre en lumière des 
Figure 1. Localisation des cas d'étude retenus et photographies illustrant la diversité des paysages.

Les trois terrains principaux sont représentés en orange : le Montmorillonnais (photo A), zone intermédiaire avec un maintien d'exploitations de polyculture-élevage ; le bassin Tarn-Aveyron (photo B), spécialisation en grandes cultures dans des zones de vallées et en élevage de ruminants dans des zones plus vallonnées avec une forte augmentation du maïs ; la Bresse (photo C), territoire de systèmes d'élevage diversifiés disposant de signes de qualité et ayant aussi des systèmes de culture.

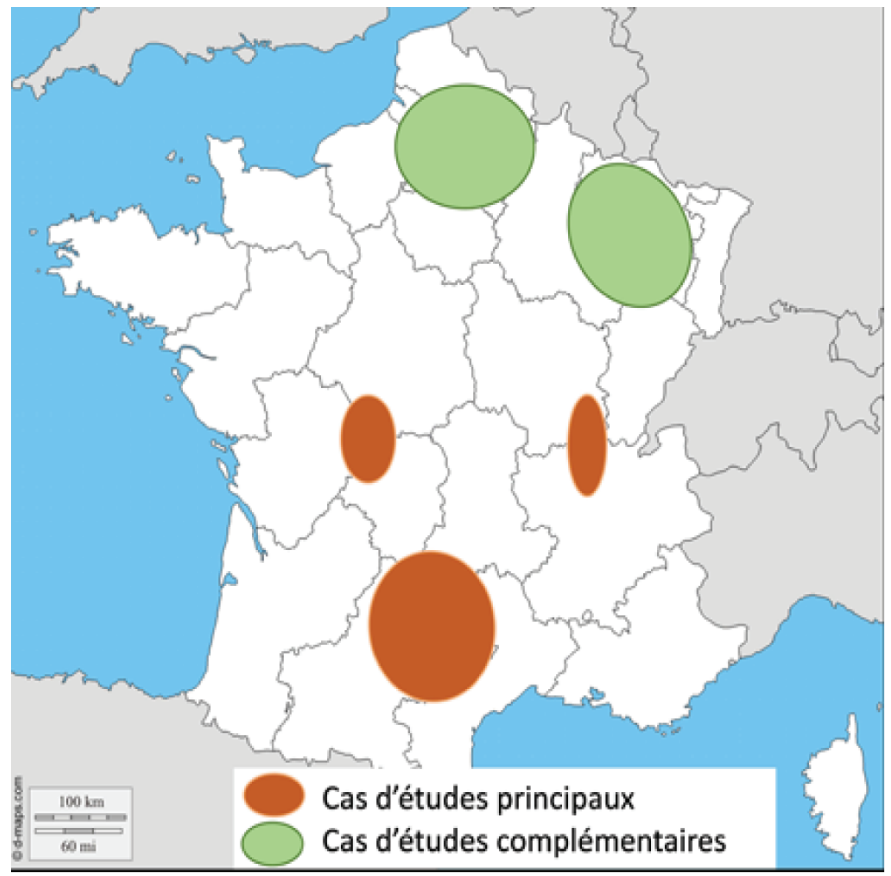

A
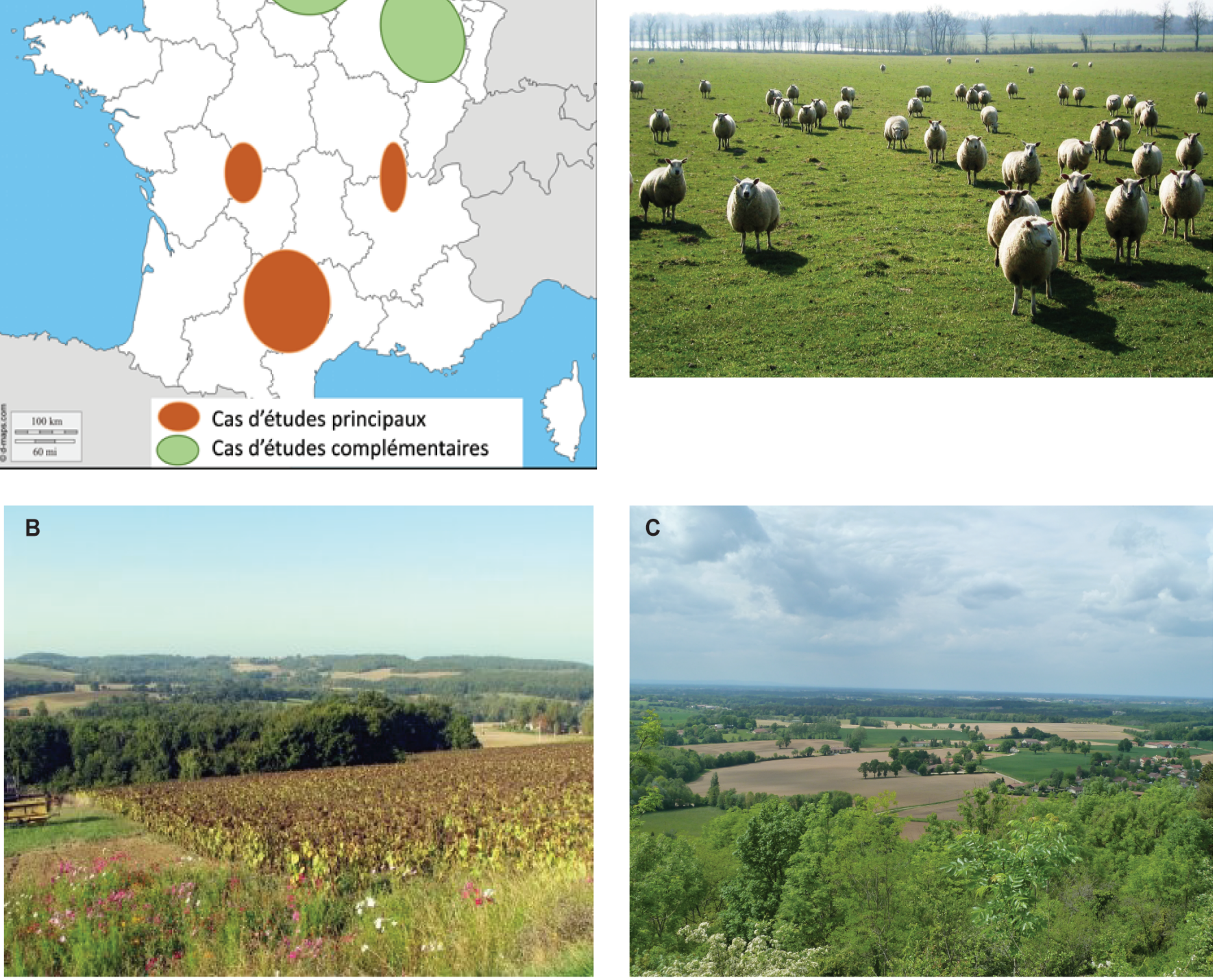

Figure 2. Trajectoire d'évolution générale des systèmes d'élevage dans le Montmorillonnais.

De 1950 à 1970 :

Très fort développement de l'élevage ovin

Arrivée massive de migrants de l'ouest développant l'élevage bovin
Depuis 1980 :

Lent mais constant déclin de l'élevage ovin

Développement des grandes cultures

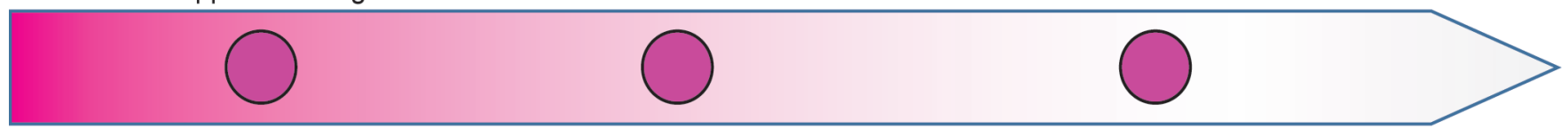

De 1970-1990 :

Intensification bovine et ovine

Désaisonnement-Apparition des premières

difficultés économiques 
situations de synergies ou de concurrences entre élevage et cultures dans les territoires. La formalisation du bouquet de services fourni par l'élevage dans ces trois territoires est inspirée d'une analyse en termes de système socio-écologique explicitant les impacts et services de l'élevage sur cinq interfaces principales (cf. Duru et al 2017, ce numéro).

\section{1 / Le Montmorillonnais : un territoire où l'élevage ovin est en déclin face aux grandes cultures}

a) Contexte et évolution de la polycultureélevage

Le Montmorillonnais est situé à la jonction de trois régions (Poitou-Charentes, Centre et Limousin) et s'insère dans un vaste ensemble rural. À une altitude de 100 à $200 \mathrm{~m}$, il jouxte la bordure nordouest du Massif central. Le potentiel agricole n'est pas très élevé, avec la présence de sols acides, légers en surface, hydromorphes en profondeur. Le Montmorillonnais subit fortement les influences de deux zones limitrophes dont les activités agricoles sont très spécialisées : au Sud, le Limousin, avec la production herbagère de ruminants, essentiellement allaitants (ovins et bovins) ; au Nord, les plaines de l'Indre avec de meilleurs potentiels pour la spécialisation en grandes cultures.

L'analyse de l'évolution de l'agriculture sur la zone met en évidence les causes du déclin de l'élevage et en particulier l'émergence d'une forte concurrence entre cultures et élevage. Cette région est caractérisée par une évolution de l'élevage ovin marquée par 30 ans de développement (1950-1980), puis 30 ans de déclin, sous l'effet de facteurs socioéconomiques majeurs (Jean 1986) (figure 2). Les caractéristiques des terres, peu productives, ont favorisé le développement d'un élevage extensif, avec peu de liens aux marchés extérieurs. Le système de métairie a retardé la modernisation des exploitations, par l'absence d'investissements, et maintenu ce type d'élevage extensif. Les années 1930 ont été difficiles du point de vue économique, avec la dégradation de la rentabilité de l'élevage bovin et des cultures et la raréfaction de la main-d'œuvre. Ces éléments ont favorisé les systèmes extensifs ovins sur de plus grandes structures, avec peu d'investissements. Suite à une augmentation de l'élevage ovin dans les années 1950, les difficultés économiques liées en particulier à la concurrence internationale ont initié son déclin à partir de 1970. Les exploitations se sont tournées vers l'élevage bovin lait et viande, puis vers les grandes cultures, qui, malgré les rendements limités, sont apparues très attractives par leur rentabilité (soutien spécifique de la PAC à partir de 1992) et surtout par leur moindre charge en tra- vail. Cette évolution vers les cultures, dont l'essentiel a été destiné à la vente, s'est faite au détriment des prairies permanentes dont la surface a été divisée par deux sur la période. Cette évolution rend compte d'une forte érosion des services environnementaux, avec $i$ ) les pollutions inhérentes aux grandes cultures (pesticides et fertilisants), ii) la perte de biodiversité engendrées par les prairies et les infrastructures agroécologiques associées (haies) ainsi que iii) la moindre séquestration du carbone qu'elles assurent.

b) Diversité des bouquets de services fournis par l'élevage

\section{Services d'approvisionnement}

La production ovine de cette zone est fondée sur une diversité de types de systèmes d'élevage (Benoit et al 1997, Benoit et Laignel 2011 ) avec $i$ ) des systèmes ovins traditionnels, extensifs, peu productifs et développant souvent un atelier de cultures de vente, ii) des systèmes « herbagers ", sans culture, très saisonnés mais productifs, basés une production d'herbe de qualité (prairies temporaires), iii) des systèmes " mixtes », très représentés, issus des préconisations des organisations de développement, avec deux périodes de mise bas (dont contre-saison), de gros cheptels et des grandes cultures, $i v$ ) des systèmes de contre-saison, moins fréquents et en général plus récents, avec de nouveaux génotypes ovins présentant une moindre conformation mais une meilleure capacité au désaisonnement, et de gros ateliers de grandes cultures. Un des enjeux majeurs de l'aval est de disposer d'une régularité d'approvisionnement en viande ovine sur l'ensemble de l'année (facilitée par la diversité des systèmes ovins présents) afin de disposer d'un argument commercial face aux principaux opérateurs. La création de signes officiels de qualité a aussi été un moyen d'éviter une confrontation directe avec la viande ovine standard, en apportant une plusvalue.

\section{Services environnementaux}

Les systèmes « herbagers 》 affichent un bilan positif au niveau environnemental et d'un point de vue économique et social mais n'ont pas été soutenus, voire ont été découragés par les opérateurs d'aval et les organismes de développement, car présentant une forte saisonnalité de leur production qui posait des difficultés de valorisation et de structuration des filières. Les systèmes « mixtes » pourraient aussi être potentiellement favorables du point de vue de la production de services environnementaux (Ryschawy et al 2014a) mais les interactions entre cultures et élevage restent limitées, les soles étant le plus souvent distinctes, les cultures étant conduites indépendamment des prairies et ne profitant que peu ou pas des apports d'azote et de la rupture potentielle des cycles des adventices et des maladies. Des observations comparables ont pu être faites dans d'autres systèmes de polyculture-élevage bovin lait et viande (Perrot et al 2013, Veysset et al 2014).

\section{Services de vitalité territoriale et} aspects socio-économiques

La contribution de l'élevage à l'emploi dans les exploitations, les structures de développement et les Industries AgroAlimentaires (IAA) associées, est faible dans les départements sur lesquels se situe en partie le Montmorillonnais (environ $2,3 \%$ en Indre, $2 \%$ en Vienne et en Charente et 3,9\% en Haute-Vienne) (Ryschawy et al 2015). Ces départements présentent une faible spécialisation en élevage.

\section{c) Mise en évidence de quelques synergies ou compromis}

Les principaux impacts positifs et négatifs de l'élevage dans le Montmorillonnais sont synthétisés dans la figure 3. La formalisation du bouquet de services fourni par l'élevage dans le territoire est inspirée d'une analyse en termes de système socio-écologique explicitant les impacts et services de l'élevage sur cinq interfaces principales (cf. Duru et al 2017). Les principaux effets positifs et négatifs associés sont présentés dans le tableau 1.

\section{La diversité : un élément-clé pour la production de services}

À l'échelle du territoire, la diversité des systèmes de production ovins, du point de vue de leur saisonnalité, apparait favorable en termes de services de production. À l'échelle des exploitations, la diversité des ateliers (systèmes mixtes ovins-bovins et ovins-cultures par exemple) peut également améliorer les performances, tant en termes de performances économiques $(+10 \%$ de marge brute par UGB ovine et $+30 \%$ par ha SFP, en système mixte $v s$ spécialisé ovin, à périodes de mise bas comparables, (Pierson et al 1982, Jean 1986)) que de performances environnementales (Sneessens et al 2014) via en particulier l'optimisation de l'utilisation des ressources fourragères (Dedieu et al 1990).

\section{Une forte incidence de la politique de la filière ovine sur la conduite des troupeaux et la place des cultures}

L'un des faits marquants de l'évolution est issu de l'aval de la filière qui a poussé à un désaisonnement de la production tout en maintenant, voire rehaussant les critères de qualité des agneaux, dont la conformation. Le schéma type issu de cette politique est un système de pro- 
Figure 3. Bouquet de services du système de polyculture-élevage dominant dans le Montmorillonnais selon la grange de l'Esco présentée dans l'article de Duru et al (2017).

Le pentagone central représente un territoire d'élevage avec ses éléments paysagers (haies) et les activités agro-industrielles sur lesquelles s'appuie l'élevage. Celui-ci est décrit par ses caractéristiques : espèces, densités animales et modes d'alimentation. Le mode d'usage des terres est représenté par un parcellaire à deux nuances de vert pour symboliser la diversité des prairies et à deux nuances de jaune pour représenter la diversité des rotations culturales. Au sein du territoire, les systèmes d'élevage interagissent avec cinq interfaces. Les pictogrammes explicités ci-dessous symbolisent les éléments concernés par ces interfaces. La nature et l'ampleur des effets sont représentées par une flèche sortante plus ou moins large et dont la couleur indique que ceux-ci sont positifs (flèche verte), négatifs (rouge) ou mitigés (hachures); dans ce cas, l'effet dominant borde la flèche. Sur l'interface travail et emploi, nous distinguons les emplois directs en élevage des emplois indirects (flèche vers personnage blanc). Les flèches entrantes indiquent l'utilisation d'intrants exogènes (qui symbolisent les effets délocalisés de l'élevage), des pressions liées aux marchés, ou (sur l'interface environnement et climat) que l'élevage bénéficie de services intrants (flèche verte) ou subit la pression de facteurs environnementaux (vecteurs de la grippe aviaire... ; flèche rouge).
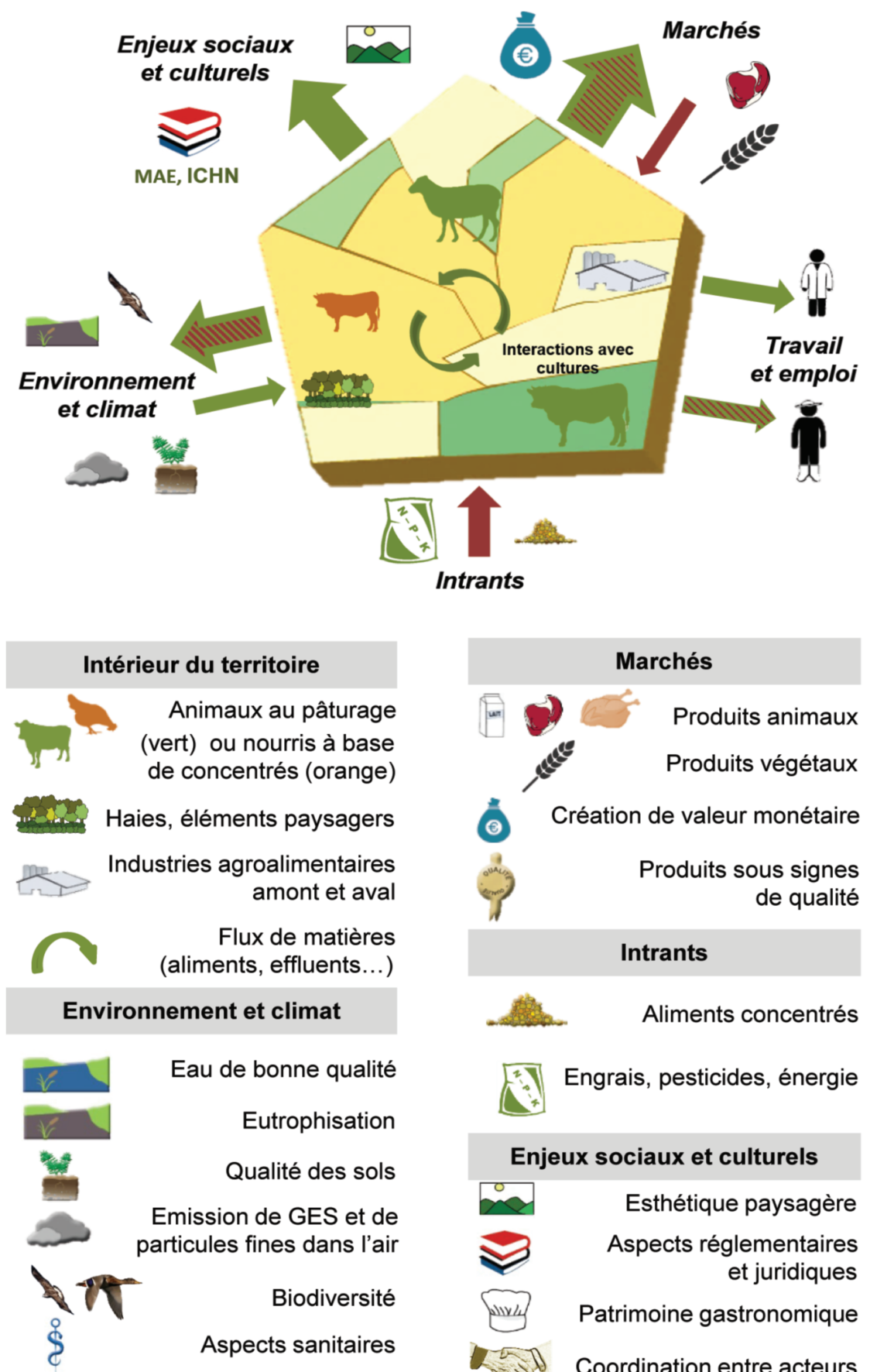

Engrais, pesticides, énergie

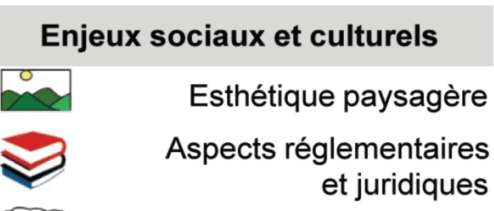

Patrimoine gastronomique

Coordination entre acteurs

Travail et emploi

Emplois directs en élevage

Emplois indirects (tourisme, IAA...) 
Tableau 1. Effets positifs et négatifs associés à l'agriculture dans le Montmorillonnais.

\begin{tabular}{|c|c|c|}
\hline $\begin{array}{c}\text { Interfaces } \\
\text { étudiées }\end{array}$ & Effets positifs & Effets négatifs \\
\hline Intrants & $\begin{array}{l}\text { - Production locale des aliments du bétail } \\
\text { si bonne intégration entre cultures } \\
\text { et élevages }\end{array}$ & $\begin{array}{l}\text { - Engrais et pesticides sur cultures et prairies } \\
\text { temporaires } \\
\text { - Effets délocalisés (usage des terres, énergie, } \\
\text { pesticides) pour concentrés protéiques } \\
\text { - Équipements } \\
\text { - Énergie pour stocks }\end{array}$ \\
\hline Travail et emploi & $\begin{array}{l}\text { - Emplois directs en élevage } \\
\text { - Maintien du tissu rural } \\
\text { - Transformation locale } \\
\text { - Emplois dans les filières }\end{array}$ & - Charge de travail en élevage élevée (astreintes) \\
\hline Marchés & $\begin{array}{l}\text { - Marchés national/européen déficitaires } \\
\text { en viande ovine offrent des débouchés } \\
\text { à des prix soutenus } \\
\text { - Produits sous signe officiel d'identification de la } \\
\text { qualité et de l'origine, bonne conformation carcasses } \\
\text { - Approvisionnement régulier sur l'année }\end{array}$ & $\begin{array}{l}\text { - Concurrence des importations d'agneaux } \\
\text { de Nouvelle-Zélande } \\
\text { - Dépendance à la conjoncture internationale } \\
\text { pour les céréales }\end{array}$ \\
\hline $\begin{array}{l}\text { Enjeux sociaux } \\
\text { et culturels }\end{array}$ & $\begin{array}{l}\text { - Esthétique du paysage } \\
\text { - Tourisme agricole } \\
\text { - Image des produits à l'herbe } \\
\text { - Patrimoine culturel et festif }\end{array}$ & - Concurrence pour l'eau (maïs) \\
\hline $\begin{array}{l}\text { Environnement } \\
\text { et climat }\end{array}$ & $\begin{array}{l}\text { - Biodiversité « commune » (bocage, prairies) } \\
\text { - Séquestration du carbone par les prairies } \\
\text { - Préservation qualité des eaux (peu d'engrais et pas } \\
\text { de pesticides sur prairies) } \\
\text { - Services intrants : légumineuses, } \\
\text { matière organique des sols, bocage }\end{array}$ & $\begin{array}{l}\text { - Usage des pesticides sur grandes cultures } \\
\text { (effet atténué par la présence de surfaces } \\
\text { herbagères) } \\
\text { - Émissions } \mathrm{CH}_{4} \text { élevées/kg de produit }\end{array}$ \\
\hline
\end{tabular}

duction (système « mixte » présenté ciavant) basé sur $2 / 3$ des mises bas au printemps et $1 / 3$ à l'automne à partir de début octobre, par synchronisation hormonale, avec des effectifs de brebis significatifs (400-500 brebis par travailleur) et l'utilisation de races conformées, mais dont la capacité de reproduction en contre saison et les caractéristiques maternelles (facilité de mise bas, allaitement des agneaux) peuvent être nettement inférieures à celles de races « rustiques » moins bien conformées. Les problèmes de travail des éleveurs ont ainsi été exacerbés (surveillance renforcée), et avec souvent une baisse de productivité des brebis (fertilité des brebis, mortalité des agneaux). La remise en cause des génotypes conformés a été réalisée tardivement, au début des années 2000. Cette évolution de la saisonnalité et de l'organisation de la production a fait surgir un besoin en céréales pour l'alimentation des troupeaux (pour les agneaux en bergerie mais aussi pour les brebis), qui, combiné à la facilité de conduite des grandes cultures, a encouragé leur développement, parfois au détriment des surfaces fourragères avec une baisse de la troupe ovine.

\section{2 / La Bresse : un territoire où les exploitations de polyculture- polyélevage se maintiennent en jouant sur les produits de qualité liés au terroir}

a) Contexte et évolution locale de la polyculture-élevage

La Bresse est une région naturelle à cheval sur trois départements : Ain, Saône-et-Loire et Jura pour une petite part. Elle est marquée par une forte identité liée à la polyculture-élevage, à l'appellation volaille de Bresse protégée depuis les années 1930 et à la culture ancienne du maïs, principalement destinée à l'élevage. La Bresse est bordée par d'autres régions à fortes identités qui l'ont influencée (système Comté à
l'Est, Charollais à l'Ouest...). L'analyse de l'évolution de l'agriculture sur la zone met en évidence une synergie entre élevage labellisé et cultures, avec une cohabitation entre cultures et élevage à l'intérieur des exploitations, mais aussi, de plus en plus, entre exploitations spécialisées soit en grandes cultures, soit en élevage. À la fin du XIXème siècle, le système bressan se caractérisait déjà par une polyculture-polyélevage associant lait, volaille, porcs et maïs au sein de chaque exploitation (figure 4). Les cultures et le lait étaient essentiellement destinés à l'alimentation des animaux. Le lait jouait également un grand rôle pour l'autoconsommation et dans le budget des familles. L'analyse de l'évolution de ce système permet de montrer en quoi l'élevage à haute valeur patrimoniale a pu se maintenir localement.

L'entre-deux-guerres a été marqué par l'apparition de coopératives laitières spécialisées dans la production de beurre et par l'obtention d'une appellation 
Figure 4. Trajectoire d'évolution générale des systèmes d'élevage en Bresse.

1950 - 1960 :

Petites exploitations

de polyculture-polyélevage

diversifiées associant

lait, volaille, porc et maïs
1980-1990 :

Valorisation de l'image traditionnelle

des produits - mise en place de SIQO et prise

de conscience du recul du bocage
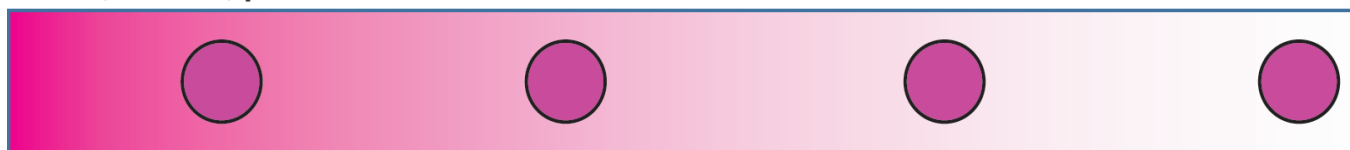

1970-1980 :

Intensification et spécialisation

des exploitations avec image

régionale traditionnelle dévalorisée
1990 - 2010 :

Concurrence forte entre

agriculture et urbanisation

Figure 5. Bouquet de services fournis par le système de polyculture-polyélevages dominant en Bresse selon la grange de l'Esco présentée dans l'article de Duru et al (2017).

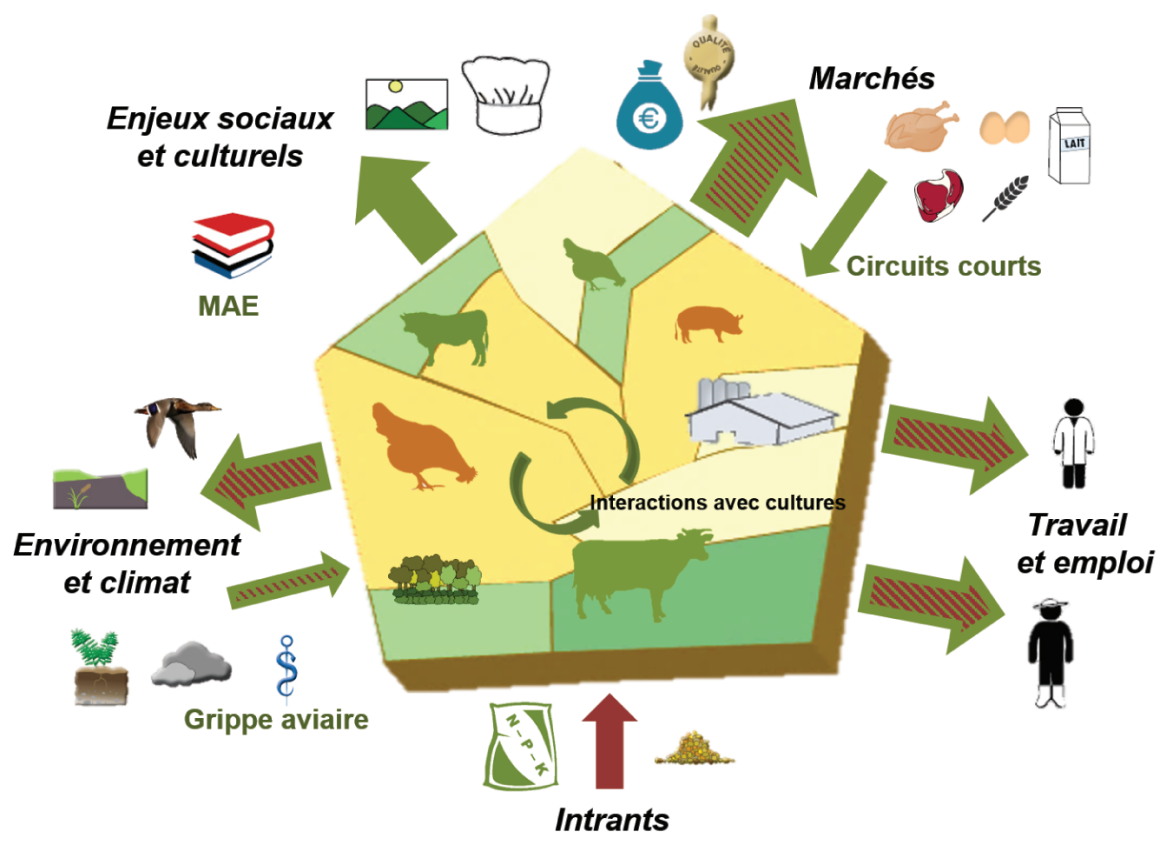

d'origine relative à la volaille de Bresse (Delfosse 1993). À partir de 1960, une crise de la main-d'œuvre, liée à l'exode rural, a remis en cause le « système bressan ». Une partie des exploitations s'est intensifiée (en particulier pour la volaille). Les outils de transformation se sont développés, notamment par le biais de coopératives. Néanmoins, des pôles de résistance à l'intensification ont émergé.

À partir des années 1980, « les traditions » ont commencé à être valorisées notamment à travers la gastronomie et des structures muséales valorisant les produits de terroir (Plet et Delfosse, 1992). Les exploitations se sont spécialisées dans l'élevage laitier, la céréaliculture ou l'élevage avicole, avec une tendance au passage de l'élevage laitier à l'élevage bovin viande suite à l'instauration des quotas laitiers. Cette période s'est également caractérisée par un début de prise de conscience du recul du bocage et de la nécessité de le mettre en valeur. Depuis le début des années 2000, une nouvelle période se dessine : une pression urbaine notable s'amorce autour de Bourg-enBresse, l'élevage de volaille rencontre des difficultés (chute du nombre d'éleveurs), tout comme les structures de transformation laitière, qui toutefois, vont valoriser la crème et le beurre de Bresse sur le modèle de l'AOP volaille.

\section{b) Diversité des bouquets de services} fournis par l'élevage

\section{Services d'approvisionnement}

Au recensement de 2010, les produits animaux fournis par les exploitations bressanes sont divers. Néanmoins, les productions en AOP volaille de Bresse sont en déclin et les productions ovines et caprines sont très faibles. Les produits issus de l'élevage sont commercialisés et transformés par différents canaux : les industries agroalimentaires (coopéra- tives et privées), les transformations artisanales (charcuterie notamment) et à la ferme avec vente directe.

\section{Services environnementaux}

Le maintien du bocage et des prairies est lié à celui des élevages bovin et avicole. Aussi, entre 2000 et 2010, la disparition d'un nombre élevé d'exploitations laitières a contribué à l'augmentation des surfaces en céréales. Néanmoins les cahiers des charges des AOP Volaille de Bresse et crème et beurre de Bresse contribuent au maintien des prairies et du bocage, en spécifiant notamment un linéaire minimal de haies par hectare.

\section{Services culturels et patrimoniaux}

L'élevage joue en Bresse un rôle particulièrement important en termes culturels et patrimonial. Le nombre des AOP l'atteste, mais aussi la reconnaissance gastronomique des produits et leur valo- 
risation par les chefs cuisiniers renommés dans la Bresse et au-delà. La volaille de Bresse est reconnue comme un produit de luxe. Les crème et beurre de Bresse sont également valorisés par les circuits gastronomiques régionaux. Des manifestations festives d'envergure régionale et nationale valorisent également l'élevage.

\section{Services de vitalité territoriale et aspects socio-économiques}

Le nombre d'emplois directs et induits par l'agriculture, et notamment l'élevage est important. En Bresse de l'Ain, selon la Chambre d'Agriculture, 2300 emplois sont liés en 2010 à l'agriculture dont une très large part liée aux filières animales : $15 \%$ pour la filière lait, $35 \%$ la filière viande, $3 \%$ des coopératives d'approvisionnement et $25 \%$ de plats préparés. Les emplois générés tiennent à l'existence d'infrastructures importantes avec des abattoirs et des laiteries. La vitalité de l'élevage local a permis à la ville de Bourg-en-Bresse de garder un foirail qui est le premier marché bovin de France. c) Mise en évidence de quelques synergies ou compromis

Les principaux impacts positifs et négatifs des systèmes d'élevage en Bresse sont repris graphiquement dans la figure 5 et détaillés dans le tableau 2 .

Cohabitation entre plusieurs types d'agriculture : entre complémentarité et compétition

Les systèmes traditionnels sont fragiles face aux systèmes intensifs (Hirzack et al 2005), mais les productions dites de terroir commencent à avoir des stratégies communes au moins en termes d'image. Les exploitations mixtes (bovins-lait/volaille), qui faisaient l'originalité de la Bresse, reculent (tensions en termes d'organisation du travail) et les rares exploitations maintenant un élevage mixte sont souvent collectives. D'autres formes d'association entre élevages existent (volaille et bovins-viande par exemple). Les exploitations laitières sont également secouées par la crise du lait. Certes, l'AOP beurre et crème de
Bresse constitue une chance importante de valorisation, mais n'assure pas encore une rentabilité suffisante. Les crises sanitaires, et notamment celle du virus de la grippe aviaire, ont pénalisé les élevages de volailles déjà peu attractifs pour les éleveurs malgré leur renommée. L'engouement pour les circuits courts près de Bourg-en-Bresse et en lien avec la métropole lyonnaise peut constituer une chance pour les productions animales avec des transformations à la ferme de la viande et des charcuteries (parfois sur de grosses exploitations) mais aussi pour la volaille AOP, même si elle s'écoule aussi beaucoup par des canaux de commercialisation de luxe (restaurateurs et bouchers haut-de-gamme).

Enfin, l'importance de la pression foncière urbaine, notamment dans le sud de la Bresse, peut remettre en cause les systèmes fondés sur la complémentarité entre culture et prairie, en compromettant les capacités d'auto-approvisionnement et les possibilités d'épandage des effluents (Chambre d'agriculture de l'Ain, 2015).

Tableau 2. Effets positifs et négatifs associés à l'agriculture en Bresse.

\begin{tabular}{|c|c|c|}
\hline Intrants & $\begin{array}{l}\text { - Production locale des aliments } \\
\text { du bétail s'il y a une bonne intégration } \\
\text { entre cultures et élevages }\end{array}$ & $\begin{array}{l}\text { - Effets délocalisés pour production des } \\
\text { concentrés protéiques } \\
\text { - Pesticides sur les grandes cultures } \\
\text { - Équipements, énergie pour stocks }\end{array}$ \\
\hline Travail et emploi & $\begin{array}{l}\text { - Emplois directs en élevage } \\
\text { - Vitalité territoriale } \\
\text { - Diversité des filières } \\
\text { - Emplois dans la transformation } \\
\text { et la commercialisation des produits } \\
\text { animaux }\end{array}$ & $\begin{array}{l}\text { - Déclin du nombre d'éleveurs } \\
\text { de volailles et fragilité des exploitations } \\
\text { lait-volailles liée à de forts besoins } \\
\text { de main-d'œuvre } \\
\text { - Pénibilité (abattoirs...) }\end{array}$ \\
\hline $\begin{array}{l}\text { Enjeux sociaux } \\
\text { et culturels }\end{array}$ & $\begin{array}{l}\text { - Identité culturelle (volaille de Bresse), } \\
\text { pêche en étangs, chasse } \\
\text { - Patrimoine gastronomique, image } \\
\text { des produits } \\
\text { - Esthétique des paysages }\end{array}$ & - Conflits pour la gestion de l'eau \\
\hline
\end{tabular}




\section{3 / Le Bassin Tarn-Aveyron : des échanges possibles entre exploi- tations spécialisées de cultures et d'élevage.}

a) Contexte et évolution de l'agriculture dans le Bassin Tarn-Aveyron

Le territoire du bassin Tarn-Aveyron est fortement marqué par la présence de l'agriculture (55\% de la SAU). Il recoupe principalement les départements du Tarn et de l'Aveyron ainsi que le Tarnet-Garonne et l'est du Lot. Dans la partie ouest du bassin, les grandes cultures se sont développées au dépend de l'élevage ; la monoculture de maïs semences irrigué pose en particulier des problèmes de gestion quantitative de l'eau (Murgue et al 2015). Dans la partie nord-est, l'élevage herbager est majoritaire, mais repose en partie sur l'achat de concentrés.

Trois grandes périodes d'évolution des exploitations sont distinguées depuis 1950 et permettent de montrer en quoi les grandes cultures et l'élevage se sont déconnectées spatialement, tant au niveau des exploitations que du territoire. De 1950 à 1970, les exploitations de polyculture-élevage étaient diversifiées (figure 6), avec deux à quatre ateliers de production : veaux sous la mère avec la race locale Gasconne, atelier de production porcine/ovine et/ou de volailles, céréales pour la vente, cultures fourragères avec pâturage (Ryschawy et al 2013). De 1970 à 1990, les exploitations se sont spécialisées sous l'influence des filières et des marchés, principalement vers la production laitière ou allaitante, et à adopter des races spécialisées, les ateliers annexes de monogastriques étant massivement abandonnés. La production traditionnelle de veaux sous la mère a laissé place à celle de jeunes bovins maigres à destination de l'Europe du Sud, sauf pour la filière Label Rouge Veau de l'Aveyron qui s'est développée (RGA, 2010). Des innovations techniques telles que l'ensilage d'herbe ou de maïs ont permis d'intensifier la production animale. L'aménagement des terres comme le drainage a permis de produire des cultures assolées en fonds de vallées. D'autres orientations de productions comme celles de tournesol ou de colza ont été prises ; l'implantation de soja, sorgho est restée marginale. Enfin, de 1990 à aujourd'hui, une tendance à l'agrandissement des exploitations a été observée, leur spécialisation se poursuivant. Cette tendance est liée à la diminution continue et régulière de la maind'œuvre familiale conduisant à la nonreprise de certaines exploitations (Gambino et al 2012) et à une simplification des pratiques (Hostiou et al 2014).

\section{b) Diversité des bouquets de services fournis par l'élevage}

\section{Services d'approvisionnement}

Dans l'étude des services rendus par l'élevage en France, l'Aveyron a été considéré comme produisant $1,7 \%$ des kilocalories produites au niveau français ce qui le place au $15^{\text {ème }}$ rang des départements français en termes de production d'élevage (Ryschawy et al 2015). En revanche, le Tarn-et-Garonne et le Tarn n'ont pas été étudiés car trop peu spécialisés en élevage. Les élevages bovins allaitants (traditionnels) et ovins laitiers (avec Roquefort) se sont très bien maintenus alors que les élevages bovins laitiers et ovins allaitants ont largement diminué (RGA, 2010). L'augmentation des surfaces de maïs dans les exploitations laitières, y compris sur des terres peu favorables à son implantation, est marquante (RGA, 2010). Aujourd'hui, la part des exploitations de polyculture-élevage est de 5,5\% en Aveyron et 17,0\% dans le Tarn-et-Garonne.

\section{Services environnementaux}

L'Aveyron, qui concentre la majeure partie de l'élevage du bassin TarnAveyron, consacre 50,3 et 26,3\% de sa surface agricole respectivement aux prairies temporaires et prairies permanentes (RGA, 2010, Ryschawy et al 2015), lesquelles favorisent notamment le maintien de la qualité de l'eau et des sols, et la biodiversité. Néanmoins, la Surface Toujours en Herbe a diminué dans l'Aveyron
(- $15 \%$ entre 2000 et 2010$)$ au profit des prairies temporaires (RGA, 2010). Le retournement de prairies permanentes et le faible niveau d'autonomie des systèmes d'élevage, principalement laitiers, sont préoccupants pour la biodiversité et la qualité de l'eau. Dans le Tarn-etGaronne, la présence d'élevage est plus diffuse, avec des exploitations plus spécialisées en grandes cultures.

\section{Services de vitalité territoriale et aspects socioéconomiques}

Dans l'Aveyron, la contribution de l'emploi associé à l'élevage dans les exploitations, les IAA, le conseil, la recherche et développement, représente $12,9 \%$ de la population active (Ryschawy et al 2015). Ces chiffres restent très variables avec des zones d'emploi denses et attractives via la présence de labellisation de qualité, comme dans la zone de Roquefort. Bien que beaucoup de surfaces soient dédiées aux ruminants, l'élevage de monogastriques, et en particulier de canards et oies grasses, apporte une très forte valeur ajoutée au territoire et crée de nombreux emplois pour la transformation des produits. Ces emplois ne sont pas nécessairement attractifs car peu qualifiés et rémunérés.

\section{c) Mise en évidence de quelques synergies ou antagonismes.}

Les principaux impacts et effets négatifs et positifs de l'élevage dans le territoire du bassin Tarn-Aveyron sont représentés dans la figure 7 et le tableau 3 .

La coexistence de systèmes de production contrastés peut limiter certains problèmes environnementaux liés à la spécialisation des territoires

Le maintien d'exploitations de polyculture-élevage est souvent conditionné par la main-d'œuvre disponible (Martin et al 2016). L'élevage est souvent défavorisé du fait d'une demande importante en main-d'œuvre et des problèmes d'organisation du travail. De plus, dans des exploitations où l'élevage a déjà disparu,

Figure 6. Trajectoire d'évolution générale des systèmes d'élevage dans le bassin Tarn-Aveyron.

1950 - 1970 :

De petites exploitations

de polyculture élevage diversifiées
1990 - 2010 :

Une phase d'agrandissement et de simplification des pratiques

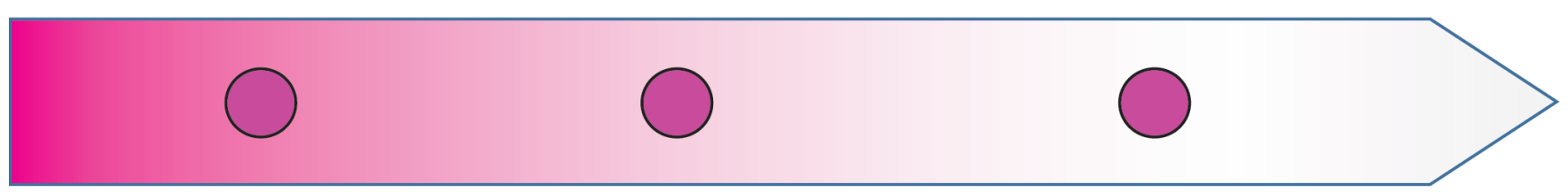

1970-1990

Une phase de spécialisation

des exploitations 
Figure 7. Bouquet de services fournis par le système de polyculture-élevage dans le bassin Tarn-Aveyron selon la grange de l'Esco présentée dans l'article de Duru et al (2017).

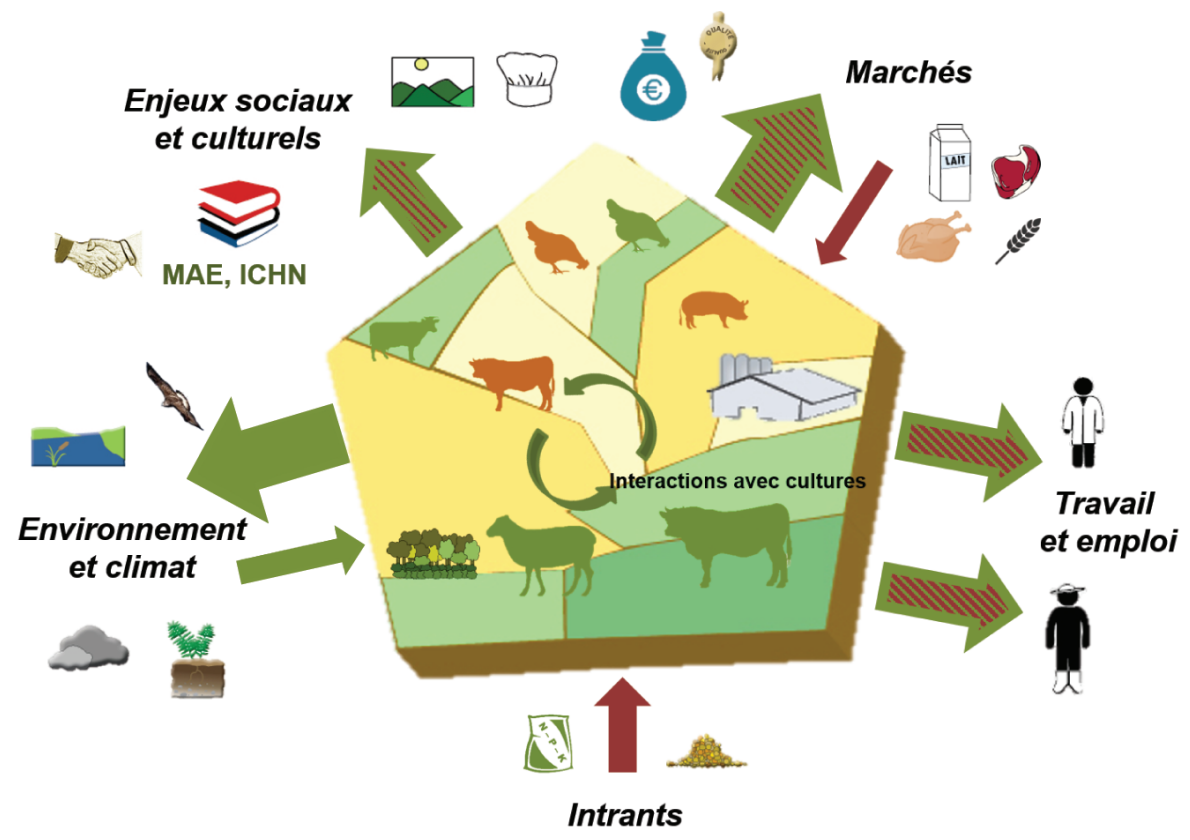

Tableau 3. Effets positifs et négatifs associés à l'agriculture dans le bassin Tarn-Aveyron.

\begin{tabular}{|c|c|c|}
\hline Interfaces étudiées & Effets positifs & Effets négatifs \\
\hline Intrants & $\begin{array}{l}\text { - Production locale des aliments } \\
\text { du bétail s'il y a une bonne intégration } \\
\text { entre cultures et élevages }\end{array}$ & $\begin{array}{l}\text { - Effets délocalisés de l'élevage (usage } \\
\text { des terres, énergie, N, pesticides) pour } \\
\text { concentrés protéiques } \\
\text { - Pesticides sur cultures } \\
\text { - Énergie pour stocks }\end{array}$ \\
\hline Travail et emploi & $\begin{array}{l}\text { - Emplois directs en élevage, vitalité } \\
\text { territoriale } \\
\text { - Diversité des filières } \\
\text { - Emplois dans transformation } \\
\text { et commercialisation des produits animaux, } \\
\text { coopératives }\end{array}$ & $\begin{array}{l}\text { - Main-d'œuvre peu qualifiée dans la } \\
\text { transformation, pénibilité } \\
\text { - Charge de travail élevée en élevage }\end{array}$ \\
\hline Marchés & $\begin{array}{l}\text { - Production de masse associée } \\
\text { à produits transformés avec haut potentiel } \\
\text { de valeur ajoutée (signe officiel d'identification } \\
\text { de la qualité et de l'origine, vente directe) } \\
\text { avec une demande soutenue }\end{array}$ & $\begin{array}{l}\text { - Dépendance vis-à-vis de la conjoncture } \\
\text { internationale pour céréales } \\
\text { - Saisonnalité de la production d'herbe } \\
\text { - Vente de produits non finis (broutards) }\end{array}$ \\
\hline $\begin{array}{l}\text { Enjeux sociaux } \\
\text { et culturels }\end{array}$ & $\begin{array}{l}\text { - Esthétique du paysage, tourisme agricole } \\
\text { - Image des systèmes de production } \\
\text { et des produits locaux } \\
\text { - Patrimoine gastronomique, culturel } \\
\text { et festif }\end{array}$ & $\begin{array}{l}\text { - Confits pour la gestion de l'eau (maïs } \\
\text { ensilage) }\end{array}$ \\
\hline $\begin{array}{l}\text { Environnement } \\
\text { et climat }\end{array}$ & $\begin{array}{l}\text { - Biodiversité (prairies permanentes, rotations } \\
\text { diversifiées) } \\
\text { - Préservation qualité des eaux (dilution } \\
\text { pesticides et engrais par prairies à l'échelle } \\
\text { territoire) } \\
\text { - Valorisation services intrants : } \\
\text { légumineuses, matière organique des sols, } \\
\text { diversité des cultures }\end{array}$ & $\begin{array}{l}\text { - GES : Émissions diluées par cultures } \\
\text { à l'échelle du territoire mais } \mathrm{CH}_{4} \text { élevé/kg } \\
\text { de produit animal } \\
\text { - Risques de destockage de carbone liés } \\
\text { au retournement des prairies (maïs ensilage) }\end{array}$ \\
\hline
\end{tabular}


Tableau 4. Analyse transversale du contexte favorisant ou non la cohabitation entre cultures et élevage dans les trois territoires de polyculture-élevage étudiés.

\begin{tabular}{|c|c|c|c|c|c|}
\hline $\begin{array}{l}\text { Cas d'étude } \\
\text { considéré }\end{array}$ & $\begin{array}{l}\text { Intégration entre } \\
\text { cultures et élevage }\end{array}$ & $\begin{array}{c}\text { Contexte } \\
\text { pédoclimatique }\end{array}$ & $\begin{array}{c}\text { Contexte } \\
\text { économique }\end{array}$ & $\begin{array}{l}\text { Contexte } \\
\text { Social }\end{array}$ & Contexte politique \\
\hline $\begin{array}{l}\text { Montmorillonnais } \\
\rightarrow \text { Élevage de } \\
\text { viande ovine } \\
\text { standard avec une } \\
\text { place aujourd'hui } \\
\text { majeure des } \\
\text { cultures à l'échelle } \\
\text { du territoire }\end{array}$ & $\begin{array}{l}\text { Coexistence locale } \\
\text { avec une forte } \\
\text { concurrence et une forte } \\
\text { diminution de l'élevage } \\
\text { de ruminants produisant } \\
\text { essentiellement de la } \\
\text { viande standard }\end{array}$ & $\begin{array}{l}\text { Le potentiel agricole } \\
\text { n'est pas très élevé, } \\
\text { avec la présence de } \\
\text { terres de brandes } \\
\text { (sols acides, légers } \\
\text { en surface, } \\
\text { hydromorphes en } \\
\text { profondeur) }\end{array}$ & $\begin{array}{l}\text { Production de } \\
\text { grandes cultures } \\
\text { plus attractives par } \\
\text { rapport à la vente de } \\
\text { viande ovine } \\
\text { standard (surtout } \\
\text { années 90) }\end{array}$ & $\begin{array}{l}\text { Pas d'identité } \\
\text { particulière liée } \\
\text { aux produits } \\
\text { agricoles } \\
\text { Forte charge de } \\
\text { travail en élevage }\end{array}$ & $\begin{array}{l}\text { Contexte globalement } \\
\text { favorable à la } \\
\text { spécialisation en } \\
\text { grandes cultures } \\
\text { ( } 1^{\text {er }} \text { pilier/modernisation) } \\
\text { Primes herbagères du } \\
\text { second pilier favorables } \\
\text { à l'élevage mais limitées }\end{array}$ \\
\hline $\begin{array}{l}\text { Bresse } \\
\rightarrow \text { Un élevage } \\
\text { reconnu et } \\
\text { labellisé avec une } \\
\text { alimentation locale }\end{array}$ & $\begin{array}{l}\text { Modérée avec des } \\
\text { complémentarités entre } \\
\text { cultures et élevage dans } \\
\text { les exploitations et entre } \\
\text { exploitations }\end{array}$ & $\begin{array}{l}\text { Peu favorable aux } \\
\text { grandes cultures }\end{array}$ & $\begin{array}{l}\text { Filières AOP pour } \\
\text { les produits volaille } \\
\text { de Bresse, lait et } \\
\text { beurre/Coopérati- } \\
\text { ves incitant à } \\
\text { l'intensification des } \\
\text { systèmes }\end{array}$ & $\begin{array}{l}\text { Forte identité liée } \\
\text { à la polyculture- } \\
\text { élevage, à } \\
\text { l'appellation } \\
\text { volaille de Bresse }\end{array}$ & \\
\hline $\begin{array}{l}\text { Bassin Tarn- } \\
\text { Aveyron } \\
\rightarrow \text { Élevage } \\
\text { diversifié avec de } \\
\text { nombreux SIQO, } \\
\text { mais concurrence } \\
\text { forte avec les } \\
\text { cultures de vente } \\
\text { liées à une forte } \\
\text { valeur ajoutée }\end{array}$ & $\begin{array}{l}\text { Forte concurrence entre } \\
\text { élevage et cultures avec } \\
\text { cependant des } \\
\text { perspectives de } \\
\text { collaboration locale } \\
\text { entre grandes cultures } \\
\text { et élevage }\end{array}$ & $\begin{array}{l}\text { Contexte } \\
\text { favorable aux } \\
\text { grandes cultures } \\
\text { au sud-ouest } \\
\text { (plaine) mais } \\
\text { coteaux à étés } \\
\text { secs }\end{array}$ & $\begin{array}{l}\text { Marché porteur pour } \\
\text { le maïs semences } \\
\text { Présence } \\
\text { d'industries de } \\
\text { collecte et } \\
\text { transformation de } \\
\text { produits SIQO }\end{array}$ & $\begin{array}{l}\text { Problèmes } \\
\text { sociaux autour de } \\
\text { la gestion } \\
\text { quantitative de } \\
\text { l'eau } \\
\text { Valorisation et } \\
\text { reconnaissance } \\
\text { des produits } \\
\text { animaux SIQO }\end{array}$ & $\begin{array}{l}\text { Contexte globalement } \\
\text { favorable à la } \\
\text { spécialisation en } \\
\text { grandes cultures } \\
\text { ( } 1^{\text {er }} \text { pilier/modernisation) } \\
\text { Primes herbagères du } \\
\text { second pilier favorables } \\
\text { à l'élevage mais limitées }\end{array}$ \\
\hline
\end{tabular}

les compétences techniques sont souvent perdues et il sera difficile d'envisager son retour. En revanche, il existe dans le bassin Tarn-Aveyron des territoires où coexistent encore des exploitations céréalières et d'élevage. Leur coexistence permet de maintenir une certaine diversité des paysages, favorable à la fourniture de services écosystémiques.

L'évolution des filières pour accompagner la diversification des systèmes de cultures et des signes de qualité

Pour améliorer la qualité de leurs sols, des céréaliers locaux insèrent des légumineuses et diversifient leurs rotations et assolements. Néanmoins, peu de débouchés pour les légumineuses existent localement. La question de la mise en place de filière de valorisation de la luzerne ou des méteils associant céréales et légumineuses est actuellement étudiée (Bedoussac et al 2013 ), les grains peuvent aussi être triés ou achetés mélangés par certaines coopératives. Enfin, au-delà de l'agrandissement des structures, le territoire est caractérisé par un essor de la vente directe mais surtout une progression des productions sous signe officiel de qualité d'origine (SIQO) qui concernent à la fois les ruminants et les monogastriques (IGP veaux d'Aveyron et du Ségala, AOP Roquefort, AOP Laguiole...). Ces labels permettent un maintien et une bonne valorisation de produits de l'élevage qui restent reconnus et concurrentiels par rapport aux grandes cultures.

\section{2 / Analyse transversale des cas d'étude : des bouquets de services rendus par l'élevage limités par son recul dans les territoires de cohabitation entre cultures et élevage}

L'analyse transversale de ces différents cas d'étude souligne $i$ ) que la polyculture-élevage recouvre un large panel d'exploitations avec des niveaux d'intégration agronomiques très variables entre élevage et cultures allant d'une simple coexistence à des réelles synergies (Moraine et al 2014) combinées à ii) des stratégies d'agriculteurs très variées qui contribuent à expliquer des trajectoires allant ou non vers l'autonomie via une coordination plus ou moins forte entre cultures et élevage. Ainsi, il paraît essentiel de définir précisément le type de polyculture-élevage étudié pour réellement capitaliser sur la diversité des cultures et de l'élevage. Néanmoins, des transversalités peuvent être mise en avant en termes d'opportunités et de contraintes, qui se posent pour l'élevage dans des territoires concurrencés par les cultures (tableau 4).

À l'inverse de ce que l'on observe dans les territoires à " haute densité animale», la place de l'élevage a fortement diminué dans les territoires de polyculture-élevage dans lesquels l'élevage a souffert d'une forte concurrence avec les grandes cultures, plus rentables économiquement et plus simples à gérer. Aussi, dès que le contexte pédoclimatique le permettait, les grandes cultures, avec un marché et des politiques publiques porteuses, ont largement supplanté l'élevage (Ryschawy et al 2013). Ainsi, on observe dans le Montmorillonnais comme dans le bassin Tarn-Aveyron, une zone de cultures spécialisée en contexte pédoclimatique favorable et une zone spécialisée en élevage ailleurs. Cette dynamique a également conduit à un appauvrissement en matière organique des sols dans les zones de grandes cultures, aujourd'hui largement reconnu (Perrot et al 2013, Soussana et Lemaire 2014).

La diversité des types d'élevage semble être une opportunité pour les territoires de polyculture-élevage, comme on peut le voir dans le cas du Montmorillonnais avec une complémentarité technique et commerciale entre systèmes. Le cas de la Bresse vient aussi renforcer cet argumentaire avec la pertinence d'une diversité d'élevages produisant des produits de qualité labellisés et une vitalité territoriale, ainsi qu'une image valorisante associée. Dans le bassin Tarn-Aveyron, par exemple, les acteurs locaux mettent en avant la renommée et la diversité des filières de qualité pour les produits issus des systèmes herbagers et monogastriques, qui sont des piliers du patrimoine et de l'économie locale. La coexistence de ces systèmes est une richesse pour la zone, à la fois en termes de paysage, 
d'offre gastronomique pour les touristes et de qualité environnementale. Pourtant, on observe toujours une tendance à l'hyperspécialisation de petits territoires en grandes cultures par exemple dans le Montmorillonnais, où de moins en moins d'exploitations maintiennent l'élevage et les prairies associées, et en Bresse, avec une intensification des systèmes d'élevage et une menace quant à leur maintien.

Comme de nombreux travaux le soulignent, cette analyse transversale met en lumière les contraintes d'organisation du travail dans les exploitations de polyculture-élevage (Veysset et al 2005, Gédouin 2008, Ryschawy et al 2012), qui ont fortement contribué à la diminution de ce type d'exploitation. La charge de travail est généralement élevée dans les exploitations de polyculture-élevage (RA, 2010). Actuellement, elles ont une productivité du travail (exprimée en EBE/UTA non salarié) en moyenne plus faible que les exploitations de grandes cultures, et au sein de l'UE elles ne dégagent en général pas de hauts revenus à l'exception de la France, la Belgique ou l'Italie. De nombreux travaux soulignent par ailleurs les problèmes d'organisation du travail dans les exploitations de polyculture-élevage (Veysset et al 2005, Gédouin 2008, Wilkins 2008, Ryschawy et al 2012). La charge mentale est encore plus importante, compte-tenu de la gestion des pics de production en grandes cultures - importants à gérer avec potentiellement une diversité de cultures de vente et prairies plus importantes - et en élevage. Par ailleurs ces exploitations sont parfois difficiles à transmettre du fait d'un plus fort besoin en capital lié aux ateliers d'élevage et de cultures (matériel, surfaces, bâtiments...) et à un besoin spécifique de compétences.

Plus largement, le manque d'attractivité de certaines filières (volailles grasses, volailles de Bresse, lait...) pose des questions sur le maintien de l'élevage dans les territoires où cohabitent élevage et cultures. Cependant, en Bresse ou dans l'Aveyron, les exploitations d'élevage se sont maintenues grâce à des cahiers de charges SIQO et la mise en avant d'un patrimoine lié à un élevage local et autonome.

\section{3 / Les territoires où cohabi- tent cultures et élevage offrent de nouveaux leviers d'action pour gérer les compromis entre services}

En lien avec les contraintes et opportunités illustrées par notre analyse transversale, différents leviers d'action techniques et organisationnels peuvent être envisagés pour améliorer les bouquets de services de ces exploitations et des territoires où cohabitent cultures et élevages. Le tableau 5 reprend les principaux leviers proposés. Ils s'inscrivent dans les deux voies de modernisation écologique présentées dans (Duru et al 2017). La première voie repose sur une amélioration de l'efficience des systèmes ou une substitution des intrants. Ils s'appuient sur une optimisation de l'alimentation animale (rations) et de la gestion des effluents (banques de lisiers au niveau des territoires). Ces leviers sont similaires à ceux détaillés dans l'article de Dourmad, ce numéro, sur les zones à haute densité animale. La seconde voie correspond à une valorisation des services écosystémiques reposant sur une reconception des systèmes. Les leviers d'action reposent alors sur la mise en adéquation du chargement animal avec les surfaces en cultures pour améliorer la gestion des effluents et favoriser l'autonomie de l'alimentation animale (Duru et al 2017). Ceci doit permettre de favoriser la diversité des utilisations (cultures/ prairies/infrastructures agroécologiques) dans l'espace et dans le temps par la coordination entre élevage et cultures (Moraine et al 2014).

\section{1 / Combiner un portfolio de pratiques pour mieux coordonner animaux-cultures-prairies-arbres au niveau des exploitations de poly- culture-élevage}

a) Favoriser la diversification des ressources mobilisées pour alimenter les animaux

La diversification des rotations et des assolements afin de favoriser l'autonomie alimentaire des troupeaux constitue un levier majeur pour favoriser la modernisation écologique de la polycultureélevage. La teneur en matière organique des sols de cultures est généralement améliorée lorsque des prairies temporaires sont introduites dans les rotations, en particulier lorsqu'il s'agit de mélanges graminées-légumineuses (Soussana et Lemaire 2014). Une option pertinente est d'introduire des inter-cultures fourragères, par exemple en implantant du trèfle violet entre deux céréales d'hiver ou un méteil avoine-vesce pâturé avant des cultures d'été (Ryschawy et al 2014b). Une autre pratique est de maintenir les résidus de culture au sol après la récolte et d'en incorporer une partie (Kragt et Robertson 2014). La valorisation des cultures et inter-cultures par les animaux peut donner plus de flexibilité au système. Une culture contaminée par des adventices peut par exemple être ensilée ou pâturée directement par les animaux, plutôt qu'être vendue. Les résidus de culture peuvent dans la plupart des cas être pâturés, comme c'est le cas chez des agriculteurs innovants du Nord-Dakota aux États-Unis (Waligora 2013), et dans de nombreux pays du Sud. Ces pratiques pourraient être développées en Europe en recherchant les espèces adaptées à une telle conduite.

Les animaux peuvent aussi être associés à des cultures pérennes dans des systèmes d'agroforesterie qui offrent une large gamme de solutions techniques pour atteindre des solutions gagnantgagnant. Les niveaux de production des vaches laitières et les atouts de tels systèmes vis-à-vis de la biodiversité et de la fourniture de services écosystémiques ont déjà été bien quantifiés dans les pays du Sud (Murgueitio et al 2011). L'association de ressources fourragères arbustives ou arborées aux prairies et cultures, très utilisées en Amérique latine, augmente la résilience aux aléas climatiques (Thornton et Herrero 2014, Nicholls et Altieri 2015). En France, on peut aussi constater que des pratiques traditionnelles d'élagage régulier d'espèces arbustives (frêne le plus généralement) continuent à être pratiquées par exemple en zone de montagne (Massif central, Pyrénées) pour alimenter les troupeaux, et particulièrement pour pallier les déficits fourragers de fin d'été en situation de sécheresse, même si le frêne peut aussi causer des problèmes d'enfrichement (Mott et al 2006). En terme de bien-être, l'arbre procure aussi de l'ombre aux animaux.

En France, des projets sont à l'étude dans le cadre par exemple du dispositif « Oasys » dans lequel arbres, arbustes et haies sont intégrés à un système bovin laitier-cultures (Novak et al 2016). Cette expérimentation est en cours dans le centre-ouest de la France pour tester un système bovin laitier performant, valorisant les ressources naturelles et adapté au changement climatique (Novak et Émile 2014). Le système mise sur la diversification du système fourrager, en utilisant en particulier des mélanges variétaux, avec un recours accru aux légumineuses, des successions de cultures pour maintenir la couverture du sol, et l'implantation d'arbustes et d'arbres pour fournir des ressources fourragères y compris au moment des sécheresses estivales. La consommation des feuillages d'arbres bas étend le bouclage du cycle des minéraux aux horizons profonds du sol qu'atteignent leurs racines. Le choix des génotypes animaux est également important afin que ceux-ci valorisent ces ressources alimentaires moins conventionnelles ; dans l'expérimentation précitée, le choix s'est porté sur un croisement de vaches Holstein, Scandinaves et Jersiaise, dont les périodes de vêlage ont été adaptées.

Dans d'autres pays, des études ont porté sur les animaux qui pâturent entre 
Tableau 5. Principaux leviers d'action proposés pour améliorer les bouquets de services fournis dans les territoires où cohabitent cultures et élevage.

\begin{tabular}{|c|c|c|}
\hline $\begin{array}{c}\text { Voies de } \\
\text { modernisation } \\
\text { écologique }\end{array}$ & $\begin{array}{c}\text { Voie } 1: \text { Recherche accrue d'efficience } \\
\text { et de substitution }\end{array}$ & $\begin{array}{c}\text { Voie } 2 \text { : Valorisation des services } \\
\text { écosystémiques }\end{array}$ \\
\hline $\begin{array}{l}\text { Leviers aux } \\
\text { niveaux } \\
\text { troupeau et } \\
\text { exploitation }\end{array}$ & $\begin{array}{l}\text { Optimiser la configuration du système } \\
\text { de production sous contraintes } \\
\text { environnementales : } \\
\text { - Optimiser l'efficience alimentaire des } \\
\text { troupeaux } \\
\text { - Recycler les coproduits dans } \\
\text { l'alimentation animale (drèches...) } \\
\text { - Optimiser la gestion des effluents } \\
\text { (traitement...) } \\
\text { - Développer des outils de décision } \\
\text { pour configurer un système de } \\
\text { production optimisé d'un point de vue } \\
\text { économique et environnemental pour } \\
\text { différents chargements }\end{array}$ & $\begin{array}{l}\text { Favoriser le lien au sol par une intégration } \\
\text { réelle entre cultures (prairies) et élevage : } \\
\text { - Diversifier les rotations et assolements } \\
\text { pour favoriser l'alimentation des } \\
\text { troupeaux: } \\
\text { - Raisonner le chargement animal en fonction } \\
\text { des potentialités du milieu } \\
\text { - Favoriser l'autonomie alimentaire des } \\
\text { troupeaux en insérant des oléo-protéagineux } \\
\text { et/ou légumineuses et prairies variées pour les } \\
\text { ruminants } \\
\text { - Développer une diversité d'intercultures } \\
\text { fourragères et/ou protéagineuses adaptées } \\
\text { localement } \\
\text { - Maintenir et incorporer au sol les résidus de } \\
\text { cultures } \\
\text { - Associer ruminants et monogastriques à des } \\
\text { cultures pérennes (sylvopastoralisme, } \\
\text { agroforesterie, parcours...) et maintenir les } \\
\text { prairies permanentes } \\
\text { - Améliorer la gestion de la fertilisation } \\
\text { organique par les animaux en fonction des } \\
\text { systèmes de cultures } \\
\text { - Développer des outils de décision et de } \\
\text { simulation pour aider les agriculteurs à } \\
\text { gérer la complexité technique et organiser } \\
\text { leur travail }\end{array}$ \\
\hline $\begin{array}{l}\text { Leviers aux } \\
\text { niveaux } \\
\text { territoire }\end{array}$ & $\begin{array}{l}\text { Développer des filières pour relocaliser } \\
\text { I'intégration entre cultures et d'élevages } \\
\text { - Développer des filières locales de } \\
\text { productions d'oléo-protéagineux et } \\
\text { légumineuses (tourteaux de colza-non } \\
\text { OGM, graines d'oléagineux, séchage de } \\
\text { luzerne...) } \\
\text { - Recycler les coproduits de cultures ou } \\
\text { déchets (de meunerie, biscuiterie...) pour } \\
\text { alimenter les monogastriques et } \\
\text { ruminants } \\
\text { - Développer des filières de gestion, } \\
\text { traitement et transport des effluents au } \\
\text { sein du territoire }\end{array}$ & $\begin{array}{l}\text { Développer des échanges locaux entre } \\
\text { agriculteurs spécialisés en grandes } \\
\text { cultures et éleveurs } \\
\text { - Raisonner la complémentarité des prairies } \\
\text { et autres utilisations du sol pour favoriser } \\
\text { l'hétérogénéité des paysages (assolements } \\
\text { en commun, construction collective des } \\
\text { assolements...) } \\
\text { - Développer des outils de décision et de } \\
\text { simulation pour aider les agriculteurs à } \\
\text { concevoir les échanges } \\
\text { - Mettre en place de banques de travail et } \\
\text { formations entre céréaliers et éleveurs } \\
\text { Valoriser et développer des territoires } \\
\text { autonomes avec une image positive pour } \\
\text { les consommateurs } \\
\text { (territoires à énergie positive, autonomie locale } \\
\text { en intrants, mosaïque paysagère diversifiée...) }\end{array}$ \\
\hline
\end{tabular}

les rangées d'arbres (González-García et al 2012) ou les rangs de vigne (Manuelian et al 2015) valorisent l'herbe et fertilisent le sol par leurs déjections ; ils évitent ainsi d'utiliser de l'énergie fossile ou des herbicides pour maîtriser la pousse de l'herbe. Le pâturage d'hiver ou l'utilisation de chlorure de lithium pour un conditionnement aversif vis-à-vis des feuilles de vigne (Manuelian et al 2015) sont des pratiques qui permettent de faire coexister l'élevage d'herbivores avec la viticulture. Les volailles peuvent aussi être intégrées avec succès dans des systèmes de cultures pérennes (encadré 1). En Afrique du Sud, des canards sont utilisés dans un vignoble pour y consommer l'herbe mais aussi les insectes et limaces qui attaquent les pieds de vigne, tandis que des travaux ont étudié les possibilités qu'offrent les canards pour désherber de manière naturelle les rizières (Falconnier et al 2012).

b) Adapter le chargement animal et le mode de gestion des effluents à la structure de l'exploitation

Bien que les études à l'échelle de l'atelier soient privilégiés pour les exploitations avec monogastriques, Baudon et al 
Encadré 1. Complémentarité entre la production d'oies gavées et différentes productions végétales (céréales, protéagineux, noix) dans une exploitation avicole de Dordogne (Bijja et al 2010 ; Thomas et al 2014).

Les oies sont alimentées à partir du pâturage et de ressources produites sur l'exploitation, leurs déjections sont valorisées dans un méthaniseur qui permet de produire du compost et de l'énergie. Cette association améliore la production de noix de $26 \%$ et la croissance des arbres de $6 \%$. Les risques de contamination des noix par Escherichia coli sont écartés si les oies sont retirées du parcours au moins deux mois avant la récolte. Par temps chaud les oies profitent également de l'ombre des noyers.

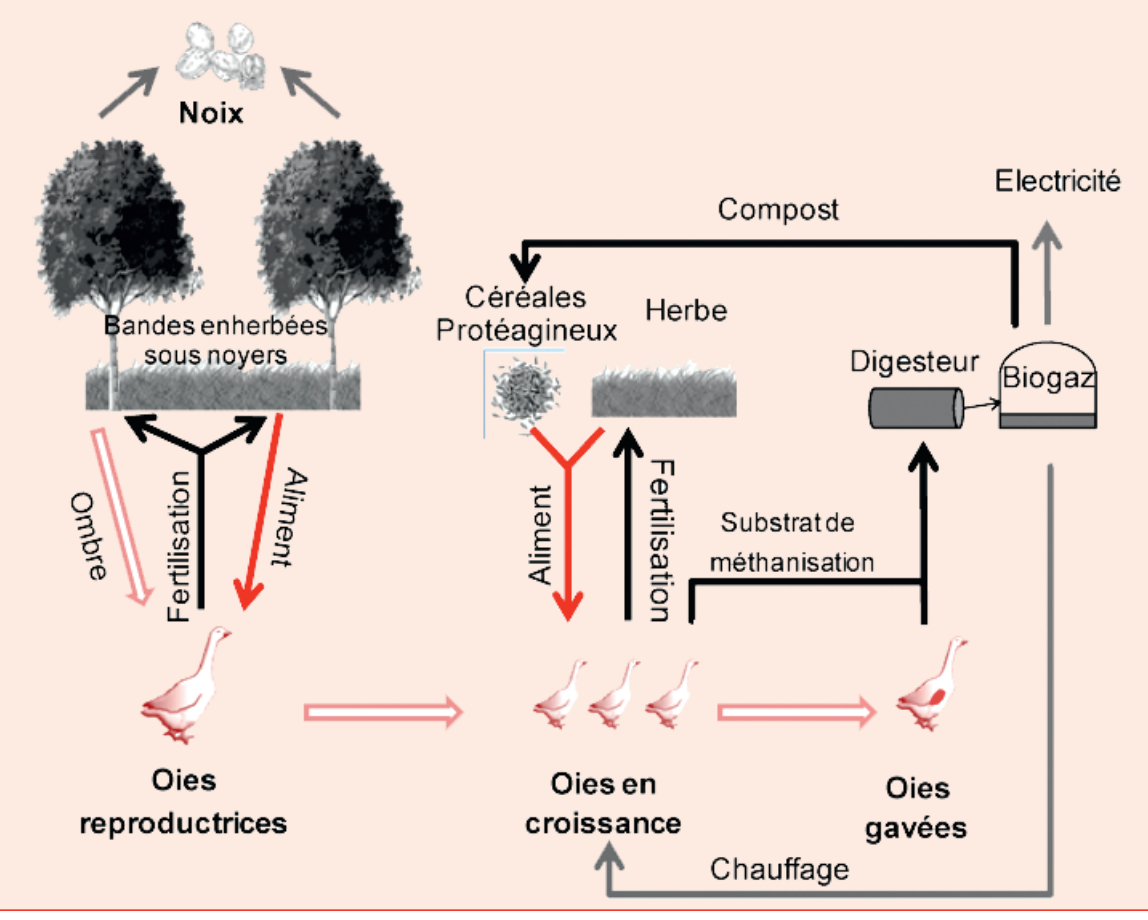

Encadré 2. Un exemple de modélisation de gestion des effluents en système de polyculture-élevage de monogastriques.

Baudon et al ont modélisé une exploitation agricole produisant à la fois des porcs à l'engrais et des cultures de vente (Baudon et al 2005) avec pour objectif d'optimiser la configuration du système de production sous contraintes environnementales pour différents chargements. Différentes filières de gestion des effluents ont été testées. Jusqu'à 50 porcs engraissés/ha/an, soit une charge organique d'environ $140 \mathrm{~kg} \mathrm{~N} / \mathrm{ha}$, la filière lisier offre la marge brute la plus élevée. Entre 60 et 80 porcs/ha les filières mixtes lisier/fumier et lisier/lisier composté sont les plus intéressantes, et au-delà de 90 porcs/ha, les stratégies avec compostage de lisier ou traitement anaérobie offrent les meilleurs résultats. Les bilans d'azote et de phosphore sont plus excédentaires pour les filières fumier, alors que la volatilisation d'ammoniac est plus importante pour les filières lisier. La quantité de travail est supérieure pour les filières fumier. Cette étude confirme l'intérêt qu'il y a à optimiser simultanément l'ensemble du système (Teffène et al 1999) du fait des relations étroites entre productions végétale et animale, à la fois pour la valorisation des déjections et pour la formulation des aliments.

(2005) ont modélisé le fonctionnement d'exploitations de polyculture-élevage avec des porcs. Ils ont montré que les systèmes porcins les plus durables sur le plan environnemental et économique présentent des chargements se situant entre 50 et 80 porcs produits/ha/an, soit pour un élevage naisseur-engraisseur, l'équivalent d'environ 2 à 3 truies et leur suite par hectare (encadré 2). Dans cette situation, 25 à $30 \%$ des effluents sont un réseau de connaissances et d'acteurs qui favorisent leur transition vers l'autonomie (Coquil et al 2014). Des outils spécifiques sont mobilisés et adaptés par les agriculteurs durant les étapes de conception du système au cours desquelles ils mettent en cohérence l'ensemble de pratiques mises en ouvre et leurs valeurs. La complexité de la gestion du système de polyculture-élevage est essentielle à considérer pour favoriser son autonomie ; elle conduit fréquemment à une reconception pas-à-pas, par essais-erreurs. Les innovations techniques doivent être co-conçues avec les acteurs locaux, pour imaginer différentes options techniques, vues comme un portfolio d'adaptations, ce qui permettrait de favoriser leur adoption ( Ryschawy et al 2014a). En outre des options/solutions peuvent également être proposées par les acteurs eux-mêmes. Différents modèles de simulation simple peuvent être utilisés à cette fin en réunion collective avec des agriculteurs pour les aider à reconcevoir leur système. Le RAMI fourrager peut être adapté à la reconception plus spécifique du système fourrager en particulier en considérant finement la productivité au long de l'année des prairies temporaires et permanentes (Martin et al 2011). L'outil CLIFS, développé au Cirad, sera plus adapté au raisonnement fin de l'itinéraire technique en grandes cultures et intégrera les monogastriques, considérant moins le système prairial (Le Gal et al 2013).

Enfin, les outils de politique publique peuvent être des leviers puissants d'orientation des systèmes de production. La PAC de 1992 a ainsi largement favorisé les systèmes de grandes cultures, malgré la création de la Prime à l'Herbe. En 2007, le « plan Barnier » a permis un rééquilibrage significatif des aides au profit de l'élevage d'herbivores, en maintenant une partie des aides couplées à l'élevage et en revalorisant les ICHN (Indemnités Compensatoires de handicaps Naturels). Plus récemment, le « paiement redistributif », en limitant l'agrandissement des exploitations, a pu favoriser la pérennité de fermes d'élevage de taille moyenne. Le «paiement vert» ou certaines MAEC (Mesures AgroEnvironnementales et Climatiques) ont pu encourager la mise en place de prairies, de nouvelles MAEC étant consacrées à la polyculture-élevage. Concernant les problèmes d'organisation du travail, des organisations collectives (GAEC, recours aux Entreprises de Travaux Agricoles, groupement d'employeurs...) peuvent être une alternative. En Picardie, des plans de réflexion/ action multi-filières sont à l'œuvre pour soutenir l'élevage (encadré 3) ; en Bresse, les acteurs locaux mettent en avant la diversité des filières de qualité. 
Encadré 3. En Picardie, des plans d'action multifilières sont à l'œuvre pour lever les contraintes d'organisation du travail.

En Picardie, l'élevage, majoritairement dans des fermes de type polycultureélevage, est en repli avec une baisse de $34 \%$ des éleveurs laitiers et une augmentation de $10 \%$ des exploitations spécialisées en cultures entre 2000 et 2010. Les préoccupations exprimées par les éleveurs sur leur travail sont de différents ordres : volumes élevés (journées chargées, fortes astreintes), charge mentale (lassitude, stress) ou encore pénibilité physique. Ainsi face aux enjeux de maintien de l'élevage en Picardie, pour les filières agricoles et alimentaires (valeur ajoutée, emploi) ainsi que pour le paysage et l'environnement, les acteurs des filières animales se sont mobilisés au sein d'un plan d'action régional «Vivre l'Élevage en Picardie » (VIP) porté par le Conseil Régional Picard. Ce programme s'est constitué autour de trois axes principaux dont un sur l'amélioration des conditions de travail et de la qualité de vie des éleveurs appelé « PACT'Élevage » (Projet pour l'Amélioration des Conditions de Travail en Élevage). Il a conduit à la mise en place d'actions de sensibilisation, d'élaboration de références et d'outils de conseil.

Encadré 4. La coordination entre exploitations spécialisées pour recréer une intégration cultures-élevage locale.

Des échanges de céréales et coproduits de cultures provenant des exploitations céréalières avec de la fertilisation organique provenant des exploitations d'élevage, éventuellement compostée, permettraient de conserver l'intérêt de la complémentarité entre cultures et élevage au niveau environnemental. Différentes formes d'intégration cultures-élevage locales ont été étudiées dans le bassin Tarn-Aveyron impliquant une zone de grandes cultures de plaine et une zone d'élevage défavorisée (Moraine et al 2016) ou impliquant de petits collectifs d'éleveurs et de céréaliers plus localisés (Moraine et al 2017, Ryschawy et al 2017). Des scénarios ont été testés avec les agriculteurs : i) développer la luzerne et les méteils protéagineux-céréales dans des systèmes de cultures à base de maïs de façon à diversifier les rotations et à réduire les besoins en eau d'irrigation et fertilisation minérale ; ii) des échanges de fertilisation organiques. En poussant la coordination à l'extrême, des assolements en commun peuvent être envisagés pour positionner chaque année au mieux les cultures, par rapport au potentiel pédoclimatique de la parcelle et aux besoins du collectif. Pour autant, il reste essentiel de considérer l'autonomie de l'exploitation en premier lieu avant d'envisager les échanges locaux entre céréaliers et éleveurs, pour limiter les effets environnementaux néfastes d'une intensification et hyperspécialisation des exploitations individuelles à l'instar de Regan et al (2015).

\section{2 / Des leviers supra-exploitation permis par la coordination locale d'exploitations}

a) Des échanges de matières entre exploitations spécialisées d'élevage et de grandes cultures

Réintroduire des animaux dans des exploitations ou dans des zones de grandes cultures semble difficile malgré quelques expériences en cours (troupeaux de moutons en Beauce (Peyraud et al 2014)). Il est cependant possible de jouer sur les complémentarités en associant des exploitations d'élevage spécialisées avec des exploitations de grandes cultures à l'échelle du territoire (Moraine et al 2016 - encadré 4). Des banques de travail entre éleveurs se sont développées dans l'Aveyron et dans le Gers et permettent aux éleveurs de se remplacer et de limiter la pénibilité de l'astreinte. Au Danemark, Asai et al (2014) ont néanmoins montré que ces échanges

nementale et sociale attendue. Dans d'autres territoires, des leviers sont à limite les impacts environnementaux. leurs compétences techniques, la confian-
(Asai et al 2014). L'organisation des filières amont/aval de l'élevage, notamment pour l'abattage des animaux et la commercialisation des produits, est aussi essentielle tout comme la répartition des subventions entre l'élevage et les grandes cultures.

b) Jouer sur la complémentarité locale de différents types d'élevage grâce aux filières

Un autre levier de développement de l'élevage dans les territoires de polyculture-élevage pourrait être fondé sur la complémentarité des systèmes d'élevage pour la fourniture des produits. Ainsi, satisfaire la filière tout en proposant des systèmes d'élevage produisant une large gamme de services pourrait passer par le renforcement de la complémentarité entre deux types de systèmes performants, en particulier du point de vue de la charge de travail et des performances techniques et économiques.

Une autre voie est la valorisation de l'image positive des produits liée à leur qualité. La complémentarité entre systèmes d'élevage permettrait de les développer afin qu'ils dépassent le simple statut de niche. Les labels territorialisés créent in fine un territoire reconnu et valorisé au niveau patrimonial, en particulier gastronomique avec des produits labellisés au sein d'un territoire typique comme cela existe par exemple dans le Lot. La concertation avec les consommateurs et l'implication des collectivités territoriales s'avèrent alors nécessaire. Un exemple qui dépasse le cadre des systèmes d'élevage est celui de la BioVallée dans la Drôme qui se fonde sur une forte incitation territoriale à la production en Agriculture Biologique, et sur la reconnaissance d'un territoire à Énergie Positive (Labussière 2014). Ce type de dynamique pourrait être proposé pour des systèmes de production intégrant cultures et élevage avec un cahier des charges basé sur alimentation locale de l'élevage et un apport de fertilisation organique locale.

\section{Conclusion} l'étude pour accroitre l'autonomie protéique des exploitations à l'échelle du territoire. Ainsi la coopérative La Dauphinoise propose à ses éleveurs de n'utiliser que des tourteaux de colza non-OGM produits localement ce qui favorise à la fois la coordination céréaliers-éleveurs, leurs performances économiques, et La réussite de tels systèmes d'échanges renvoie fortement à des questions complexes d'organisation collective comme l'implication des éleveurs et céréaliers, ce entre eux, la proximité géographique
L'analyse transversale proposée dans cet article montre qu'au-delà de sa renommée comme modèle agroécologique, la polyculture-élevage est largement remise en cause par la concurrence entre grandes cultures et élevage dans les territoires. De grandes questions se posent quant au maintien de la polycultureélevage face à $i$ ) la diminution de la maind'œuvre disponible en agriculture et les contraintes d'organisation pour coordonner élevage et cultures, ii) la perte de compétences liées à l'arrêt de l'élevage dans les exploitations et dans certains 
territoires, iii) la faible compétitivité de l'élevage par rapport aux grandes cultures et $i v)$ le manque d'attractivité de certaines filières (volailles). Enfin, la remise en cause de certains types d'élevage par le grand public peut aussi questionner sur la place de l'élevage en général (et de la polyculture-élevage en particulier), ainsi que les formes d'élevage et polyculture-élevage dans ces territoires.

Les systèmes de polyculture-élevage offrent néanmoins de nombreux leviers techniques pour favoriser les synergies lorsque les cultures et l'élevage sont réellement coordonnés d'un point de vue agronomique, pas simplement juxtaposés sans réelle intégration technique. L'intégration cultures-élevage permet d'augmenter l'autonomie en intrants des systèmes d'élevage et de cultures par deux leviers principaux : $i$ ) la diversification des assolements et des rotations, et ii) le lien au sol de l'élevage, avec la fertilisation organique des cultures et prairies. Dans des systèmes de polyculture-élevage associant agroforesterie et/ou agriculture de conservation, les fonctions du système sont multipliées : diversité de produits animaux et de cultures de vente. Les économies de gamme sur le matériel, le travail et les intrants devraient aussi permettre d'améliorer le revenu des exploitations et sa stabilité. Enfin, des pistes prometteuses considèrent les échanges locaux entre céréaliers et éleveurs mais ceux-ci restent très complexes en terme d'organisation collective et doivent considérer l'autonomie des exploitations comme condition sine qua non, et ils présentent des vrais défis organisationnels à relever.

\section{Références}

Asai M., Langer V., Frederiksen P., Jacobsen B.H., 2014. Livestock farmer perceptions of successful collaborative arrangements for manure exchange: A study in Denmark. Agricult. Sys., 128, 55-65.

Baudon E., Cottais L., Leterme P., Espagnol S., Dourmad J.Y., 2005. Optimisation environnementale des systèmes de production porcine. Journ. Rech. Porcine., 325-332.

Bedoussac L., Triboulet P., Magrini M.B., Rambault G., Foissy D., Corre-Hellou G., 2013. Conséquences de l'introduction des cultures associées céréale-légumineuse à graines dans les filières. Innov. Agronom., 32, 199-212.

Benoit M., Laignel G., 2011. Analyse sur le long terme de systèmes d'élevage ovins allaitants en France.Quelles trajectoires et quels facteurs de réussite économique? INRA Prod. Anim., 24, 211-220.

Benoit M., Laignel G., Lienard G., Dedieu B., Chabosseau J.M., 1997. Éléments de réussite économique des élevages ovins extensifs du Montmorillonnais. INRA Prod. Anim., 10, 349362 .

Bijja M., Dubois J.P., Lavigne F., Auvergne A., Arroyo J., Fernandez X., 2010. Qualité des parcours de palmipèdes : comparaison de la conduite en parcours tournants et en parcours fixe. Journ. Rech. Palmipèdes à Foie Gras. 9, 197-201.

Bonaudo T., Bendahan A.B., Sabatier R., Ryschawy J., Bellon S., Leger F., Magda D., Tichit M., 2014. Agroecological principles for the redesign of integrated crop-livestock systems. Eur. J. Agron., 57, 43-51.

Chambre d'Agriculture de l'Ain, 2015, L'agriculture en Bresse au cœur de l'économie du territoire. http://rhone-alpes.synagri.com/ CDA38/portail/01---lagriculture-en-bresse-aucoeur-de-1-economie-du-territoire

Coquil X., Béguin P., Dedieu B., 2014. Transition to self-sufficient mixed crop-dairy farming systems. Renewable Agricult. Food Sys., 29, 195-205.

Dedieu B., Jestin C., Servières G., 1990. Exploitations associant vaches laitières et brebis en Margeride. Fourrages, 124, 371-384.

Duru M., Donnars C., Ryschawy J., Therond O., Dumont B., 2017. La « grange » : un cadre conceptuel pour appréhender les bouquets de services rendus par l'élevage dans les territoires. In : Numéro spécial, L'élevage en Europe : une diversité de services et d'impacts. Dumont B. (Éd). INRA Prod. Anim., 30, 273-284.

Delfosse C., 1993. Le lait et ses produits dans la Bresse et le département de l'Ain XIX ème et $X^{\text {ème }}$ siècles : Rapport de recherche, SEGESA/ Musée des Pays de l'Ain, 78p.

Falconnier G., Mouret J.C., Hammond R., 2012. Des canards pour désherber les rizières : une intégration agriculture-élevage prometteuse pour les riziculteurs biologiques camarguais. 1 . Conférence internationale sur les systèmes de production rizicole biologique. 2012-08-27201208-30, Montpellier, France.

Gambino M., Laisney C., Vert J., 2012. Le monde en tendances. Un portrait social prospectif des agriculteurs, Centre d'Études et de Prospective, SSP, MAAPRAT. Éd. La documentation française, 124p. http://agriculture.gouv.fr/le-mondeagricole-en-tendances-un-portrait-socialprospectif-des-agriculteurs- 0

Gédouin M., 2008. Les éleveurs et leur travail en Picardie : synthèse d'enquêtes régionales et propositions pour l'action: Agro-transfert Picardie, $24 \mathrm{p}$. http://www.agro-transfert-rt.org/ wp-content/uploads/2016/02/Les \%C3\% A9leveurs et leur travail en Picardie.pdf

González-García E., Gourdine J.L., Alexandre G., Archimède H., Vaarst M., 2012. The complex nature of mixed farming systems requires multidimensional actions supported by integrative research and development efforts. Animal, $6,763-777$.

Havet A., Coquil X., Fiorelli J.L., Gibon A., Martel G., Roche B., Ryschawy J., Schaller N., Dedieu B., 2014. Review of livestock farmer adaptations to increase forages in crop rotations in western France. Agricult. Ecosys. Environ., 190, 120-127.

Hendrickson, J.R., Hanson, J.D., Tanaka, D.L., Sassenrath, G., 2008. Principles of integrated agricultural systems: Introduction to processes and definition. Renewable Agricult. Food Sys., 23, 265-271.

Hirczak M., Mollard A., 2005. Différenciation par la qualité et le territoire versus coordination sectorielle : conflit ou compromis ? L'exemple de la Bresse. Ruralia. Sciences sociales et mondes ruraux contemporains, 16/17.

Hostiou N., Chauvat S., Cornut S., 2014. Faire face à des questions de travail : les leviers mobilisés par des éleveurs laitiers. L'agriculture en famille : travailler, réinventer, transmettre. 125-143. http://dx.doi.org/10.1051/978-2-7598-1192-2.c008

Jean Y., 1986. Intensification, extensification ou diversité des systèmes de production ovine dans le Montmorillonnais. Économ. rurale, 175, 36-43.

Kragt M.E., Robertson M.J., 2014. Quantifying ecosystem services trade-offs from agricultural practices. Ecol. Econom., 102, 147-157.

Labussière O., 2014. Le regard d'un chercheur sur DORéMI et l'émergence de nouveaux collectifs pour la rénovation globale. Dorémi en Biovallée, avancement et perspectives, 11-12 juin 2014. Crest, France : 2014-06- 11. https://halshs. archives-ouvertes.fr/halshs-01239366

Le Gal P.Y., Bernard J., Moulin C.H., 2013. Supporting strategic thinking of smallholder dairy farmers using a whole farm simulation tool. Trop. Anim. Health Prod., 45, 1119-1129.

Lemaire G., Franzluebbers A.J., Carvalho P.C.D., Dedieu B., 2014. Integrated crop-livestock systems: Strategies to achieve synergy between agricultural production and environmental quality. Agricult. Ecosys. Environ., 190, 4-8.

Manuelian C.L., Albanell E., Rovai M., Caja G., Guitart R., 2015. Kinetics of lithium as a lithium chloride dose suitable for conditioned taste aversion in lactating goats and dry sheep. J. Anim. Sci., 93, 562- 569 .

Martin G., Felten B., Duru., M., 2011. Forage rummy: A game to support the participatory design of adapted livestock systems. Environ. Model. Software, 26, 1442-1453. DOI : 10.1016/j. envsoft.2011.08.013

Martin G., Moraine M., Ryschawy J., Magne M.A., Asai M., Sarthou J.P., Duru M., Therond, O., 2016. Crop-livestock integration beyond the farm level: a review. Agron. Sustain. Development, 36, 53. http://dx.doi.org/10.1007/ s13593-016-0390-X

Moraine M., Duru M., Nicholas P., Leterme P., Therond O., 2014. Farming system design for innovative crop-livestock integration in Europe. Animal, 8, 1204-1217.

Moraine M., Grimaldi J., Murgue C., Duru M., Therond O., 2016. Co-design and assessment of crop-livestock systems at the territory level: a case study in south-western France. Agricult. Sys., 147, 87-97

Moraine M., Melac P., Ryschawy J., Duru M., Therond, O., 2017. Participatory design to 
define and support a scenario of exchanges and coordination within a group of organic farmers. Ecological Indicators. Ecol. Indicat., 72, 340351.

Mottet A., Ladet S., Coqué N., Gibon A., 2006. Agricultural land-use change and its drivers in mountain landscapes: A case study in the Pyrenees. Agricult. Ecosys. Environ., 114, 296310.

Murgue C., Therond O., Leenhardt, D., 2015. Toward integrated water and agricultural land management: Participatory design of agricultural landscapes. Land Use Policy, 45, 52-63.

Murgueitio E., Calle Z., Uribe F., Calle A., Solorio B., 2011. Native trees and shrubs for the productive rehabilitation of tropical cattle ranching lands. Forest Ecol. Management, 261, 1654-1663.

Nicholls C.I., Altieri M.A., 2015. Agroecology: designing climate change resilient small farming systems in the developing world. Agroecol. Food Secur. Nutr. Proc. FAO Intern. Symp. Rome, Italy, 271-295.

Novak S., Émile J., 2014. Associer des approches analytiques et systémiques pour concevoir un système laitier innovant: de la Fée à l'OasYs. Fourrages, 217, 47-56.

Novak S., Liagre F., Émile J.C., 2016. Integrating agroforestry into an innovative mixed crop-dairy system. $3^{\text {rd }}$ Europ. Agrof. Conf. INRA, Montpellier, France pp. 396-398.

Perrot C., Caillaud D., Chambaut H., 2013. Économies d'échelle et économies de gamme en production laitière. Notes Études Économ., 37, 7-32.

Peyraud J.L., Taboada M., Delaby L., 2014. Integrated crop and livestock systems in Western Europe and South America: A review. Eur. J. Agron., 57, 31-42.

Pierson G., Baud G., Platon J.P., Gonthier G., Lienard, G., 1982. Comparaison économique d'exploitations spécialisées ovines et d'exploitations associant bovins et ovins dans le département de la Haute-Vienne CEMAGREFChambre d'Agriculture de la Haute Vienne INRA, 70p.
Plet F., Delfosse C., 1992. La valorisation des traditions. Nouvelle ressource en zone rurale fragile? L'exemple de la Bresse. Colloque international en hommage au professeur Fel, Des régions paysannes aux espaces ruraux fragiles Massif central, montagnes et campagnes européennes. Clermont-Ferrand. CERAMAC, 437446.

Regan J., Marton S., Barrantes O., Hanegraaf N., Ruane E., Berland J., Pellerin S., Nesmes T., 2015. Does the recoupling of dairy and crop production at the district scale lead to environmental benefits? A case-study approach in Europe. Eur. J. Agron., 82, 342-356.

RGA, Recensement Général Agricole 2010 Accessible à : http://agreste.agriculture.gouv.fr/ enquetes/structure-des-exploitations964/recensement-agricole-2010

Ryschawy J., Choisis N., Choisis J.P., Joannon A., Gibon A., 2012. Mixed crop-livestock systems: an economic and environmentalfriendly way of farming? Animal, 6, 1722-1730.

Ryschawy J., Choisis N., Choisis J.P., Gibon A., 2013. Paths to last in mixed crop-livestock farming: lessons from an assessment of farm trajectories of change. Animal, 7, 673-681.

Ryschawy J., Joannon A., Choisis J.P., Gibon A., Le Gal P.Y., 2014a. Participative assessment of innovative technical scenarios for enhancing sustainability of French mixed crop-livestock farms. Agricult. Sys., 129, 1-8.

Ryschawy J., Joannon A., Gibon A., 2014b L'exploitation de polyculture-élevage : définitions et questions de recherche. Une revue. Cah. Agricult., 23, 346-356.

Ryschawy J., Tichit M., Bertrand S., Allaire G., Plantureux S., Aznar O., Perrot C., Guinot C., Josien E., Lasseur J., Aubert C., Tchakerian E., Disenhaus C., 2015. Comment évaluer les services rendus par l'élevage ? Une approche méthodologique sur le cas de la France. INRA Prod. Anim., 28, 23-37.

Ryschawy J., Martin G., Moraine M., Duru M., Therond O., 2017. Designing crop-livestock integration at different levels: Toward new agroecological models? NCA, DOI 10.1007/s10705016-9815-9.
Sneessens I., Benoit M., Brunschwig G., 2014. Un cadre d'analyse pour évaluer les gains d'efficience permis par les interactions cultureélevage : une typologie des systèmes de polyculture-élevage couplée à une quantification de l'intégration. Innov. Agron., 39 127-137.

Soussana J.F., Lemaire G., 2014. Coupling carbon and nitrogen cycles for environmentally sustainable intensification of grasslands and crop-livestock systems. Agricult. Ecosys. Environ. 190, 9-17.

Teffène O., Plouchard B., Longchamp J.Y., Castaing J., Baudet J.J., Hemidy L., Landais E., Salaün Y., 1999. Optimisation de l'alimentation, de l'assolement et de la fertilisation dans des exploitations céréalières avec porcs. Méthodologie et résultats. Journ. Rech. Porcine. Paris, France, 77-84.

Thomas M., Fortun-Lamothe L., Jouven M. Tichit M., González-García E., Dourmad J.Y., Dumont B., 2014. Agroécologie et écologie industrielle : deux alternatives complémentaires pour les systèmes d'élevages de demain. In: Numéro spécial, Quelles innovations pour quels systèmes d'élevage? Ingrand S., Baumont R. (Éds). INRA Prod. Anim., 27, 89-100.

Thornton P.K., Herrero M., 2014. Climate change adaptation in mixed crop-livestock systems in developing countries. Global Food Secur., 3, 99-107.

Veysset P., Bébin D., Lherm M., 2005. Adaptation to Agenda 2000 (CAP reform) and optimisation of the farming system of French suckler cattle farms in the Charolais area: a model-based study. Agricult. Sys., 83, 179-202.

Veysset P., Lherm M., Bébin D., Roulenc M., 2014. Mixed crop-livestock farming systems: a sustainable way to produce beef? Commercial farms results, questions and perspectives. Animal, 8, 1218-1228.

Waligora C., 2013. L'AC dans le Midwest américain : la seule voie pour s'en sortir / Cécile Waligora. TCS. Techniques culturales simplifiées, 73, 18-20.

Wilkins R.J., 2008. Eco-efficient approaches to land management: a case for increased integration of crop and animal production systems. Philos. Trans. R. Soc. Lond B Biol. Sci., 363, 517-525.

\section{Résumé}

Associer productions animales et végétales conférerait des bénéfices économiques, sociaux et environnementaux aux exploitations par rapport à la spécialisation. Malgré ces intérêts potentiels, les exploitations de polyculture-élevage sont en déclin en U.E., en lien notamment avec un fort besoin de main-d'œuvre pour combiner cultures et élevage et peu d'incitations politiques. L'objectif de cet article est de montrer en quoi les grandes cultures et l'élevage entrent en concurrence dans les territoires où ils cohabitent et de proposer des leviers d'actions pour favoriser des synergies. Pour cela, nous éclairerons la diversité des bouquets de services fournis par les systèmes de polyculture-élevage dans les territoires où cohabitent grandes cultures et élevage. Une analyse transversale de trois cas d'étude français (Montmorillonnais, Bresse et Tarn-Aveyron) montre que l'élevage est plus ou moins concurrencé par les grandes cultures en fonction des contextes locaux. Cette analyse nous permet de faire émerger $i$ ) des contraintes et opportunités pour la polycultureélevage, ii) des leviers d'action pour favoriser les synergies entre grandes cultures et élevage pour mieux gérer les compromis entre services dans les exploitations et les territoires. Au niveau des exploitations comme des territoires, les systèmes de polyculture-élevage offrent de nombreux leviers techniques pour favoriser la transition agroécologique. Tout d'abord, le chargement animal doit être adapté au potentiel des terres disponibles pour favoriser le lien au sol. Une réelle intégration entre grandes cultures et élevage permet d'augmenter l'autonomie des systèmes en intrants par deux leviers principaux : la diversification des assolements et des rotations et via la fertilisation organique des cultures et prairies. Aussi, une simple cohabitation de grandes cultures et d'élevage ne permet pas d'atteindre des objectifs agroécologiques ni au niveau des exploitations, ni au niveau des territoires. Des systèmes cultureséleāvage gagnants-gagnants intégrant agroforesterie ou agriculture de conservation peuvent ouvrir de nouvelles pistes. Au niveau des territoires, les échanges entre céréaliers et éleveurs peuvent être considérés. Des voies d'améliorations organisationnelles et des choix politiques sont susceptibles d'accroitre les interrelations entre cultures et élevage au niveau de l'exploitation et du territoire. 


\begin{abstract}
Crop-livestock regions: in-between competition with cash crops and opportunities

Integrating crops and livestock could limit the environmental and economic impact of specialized agriculture. Still, integrated croplivestock farms are disappearing over the European Union, due to a lack of workforce and few political incentives. This article aims at highlighting that cash crops and livestock are more often entering into competition than being sources of synergies in territories in which they coexist. We analyzed the diversity of service bundles provided by crop-livestock farming in three French territories combining cash crops and livestock. Our transversal analysis allowed us to suggest levers for an agroecological transition based on a real integration between cash crops and livestock at the farm and beyond the farm level. First of all, the animal stocking rate should be adapted as regards the potential of the agricultural area. Combining crops and livestock favors the autonomy in inputs through two main technical levers: diversification of crop rotations and organic fertilization of crops and grasslands through animal waste. Integrating agroforestry and conservation agriculture into crop-livestock systems could favor win-win strategies. At the local level, exchanges between specialized crops and livestock farmers could be of interest. Specific organizational and political levers should be explored to favor crop-livestock integration at the farm and local level.
\end{abstract}

Ryschawy J., Benoit M., Hostiou N., Delfosse C., 2017. Quelles concurrences et synergies entre cultures et élevage dans les territoires de polyculture-élevage ? In : Numéro spécial, L'élevage en Europe : une diversité de services et d'impacts. Dumont B. (Éd). INRA Prod. Anim., 30, 363-380. 
